\title{
Modulation of BK Channel Gating by the $\beta 2$ Subunit Involves Both Membrane-Spanning and Cytoplasmic Domains of Slo1
}

\author{
Urvi S. Lee, Jingyi Shi, and Jianmin Cui \\ Department of Biomedical Engineering and Cardiac Bioelectricity and Arrhythmia Center, Washington University, St. Louis, Missouri 63130
}

\begin{abstract}
Large-conductance, $\mathrm{Ca}^{2+}$ - and voltage-sensitive $\mathrm{K}^{+}(\mathrm{BK})$ channels regulate neuronal functions such as spike frequency adaptation and transmitter release. BK channels are composed of four Slo1 subunits, which contain the voltage-sensing and pore-gate domains in the membrane and $\mathrm{Ca}^{2+}$ binding sites in the cytoplasmic domain, and accessory $\beta$ subunits. Four types of BK channel $\beta$ subunits $(\beta 1-\beta 4)$ show differential tissue distribution and unique functional modulation, resulting in diverse phenotypes of BK channels. Previous studies show that both the $\beta 1$ and $\beta 2$ subunits increase $\mathrm{Ca}^{2+}$ sensitivity, but different mechanisms may underline these modulations. However, the structural domains in Slo1 that are critical for $\mathrm{Ca}^{2+}$-dependent activation and targeted by these $\beta$ subunits are not known. Here, we report that the $\mathrm{N}$ termini of both the transmembrane (including S0) and cytoplasmic domains of Slo 1 are critical for $\beta 2$ modulation based on the study of differential effects of the $\beta 2$ subunit on two orthologs, mouse Slo1 and Drosophila Slo1. The N terminus of the cytoplasmic domain of Slo1, including the $\mathrm{AC}$ region $(\beta \mathrm{A}-\alpha \mathrm{C})$ of the RCK1 (regulator of $\mathrm{K}^{+}$conductance) domain and the peptide linking it to S6, both of which have been shown previously to mediate the coupling between $\mathrm{Ca}^{2+}$ binding and channel opening, is specifically required for the $\beta 2$ but not for the $\beta 1$ modulation. These results suggest that the $\beta 2$ subunit modulates the coupling between $\mathrm{Ca}^{2+}$ binding and channel opening, and, although sharing structural homology, the BK channel $\beta$ subunits interact with structural domains in the Slo1 subunit differently to enhance channel activity.
\end{abstract}

\section{Introduction}

Large-conductance, $\mathrm{Ca}^{2+}$ - and voltage-sensitive $\mathrm{K}^{+}(\mathrm{BK})$ channels activate in response to depolarizing membrane potentials and increases in intracellular $\mathrm{Ca}^{2+}$ (Marty, 1981). The opening of BK channels effectively repolarizes the membrane and shuts $\mathrm{Ca}^{2+}$ entry through voltage-dependent $\mathrm{Ca}^{2+}$ channels, thereby reducing intracellular $\mathrm{Ca}^{2+}$. As a consequence, $\mathrm{BK}$ channels are negative feedback regulators of membrane excitability and $\mathrm{Ca}^{2+}$ entry in neurons (Lancaster and Nicoll, 1987; Storm, 1987) and smooth muscle cells (Brayden and Nelson, 1992).

Functional BK channels are tetramers of the pore-forming Slo1 subunit that is composed of seven membrane-spanning segments ( $\mathrm{S} 0-\mathrm{S} 6$ ), in which $\mathrm{S} 1-\mathrm{S} 4$ form the voltage-sensing domain (VSD) and S5 and S6 form the pore-gate domain, and a large cytoplasmic domain (Fig. 1) (Meera et al., 1997). This cytoplasmic domain is composed of two RCK (regulator of $\mathrm{K}^{+}$conductance) domains and contains two putative $\mathrm{Ca}^{2+}$ binding sites, D367 in RCK1 and the $\mathrm{Ca}^{2+}$ bowl in RCK2 (Fig. 1) (Schreiber and Salkoff, 1997; Xia et al., 2002; Wu et al., 2010; Yuan et al., 2010).

BK channels also associate with $\beta$ subunits that are composed of two transmembrane (TM) segments with cytoplasmic termini

Received May 5, 2010; revised Sept. 24, 2010; accepted Sept. 28, 2010.

This work was supported by Epilepsy Foundation (U.S.L.) and National Institutes of Health Grants R01-HL70393 (J.C.) and R01-NS060706 (J.C.). J.C. is the Spencer T. Olin Professor of Biomedical Engineering. The mSlo1 clone was kindly provided to us by Larry Salkoff (Washington University, St. Louis, M0). The $\beta 1$ and $\beta 2$ clones were kindly provided by Robert Brenner (University of Texas Health Science Center, San Antonio, TX).

Correspondence should be addressed to Jianmin Cui, Department of Biomedical Engineering, Washington University in St. Louis, Campus Box 1097, 1 Brookings Drive, St. Louis, M0 63130. E-mail: jcui@biomed.wustl.edu.

DOI:10.1523/JNEUROSCI.2323-10.2010

Copyright $\odot 2010$ the authors $\quad 0270-6474 / 10 / 3016170-10 \$ 15.00 / 0$ and a large extracellular loop. There are four types of $\beta$ subunits, $\beta 1-\beta 4$, that have tissue-specific distributions and impart unique effect on voltage- and $\mathrm{Ca}^{2+}$-dependent activation of $\mathrm{BK}$ channels (Orio et al., 2002). The $\beta 1$ and $\beta 2$ subunits have the highest sequence homology and both increase apparent $\mathrm{Ca}^{2+}$ sensitivity (Brenner et al., 2000), but different mechanisms may be responsible for their functions; the $\beta 1$ subunit was shown to primarily modify the voltage-dependent activation, whereas the $\beta 2$ subunit shows less effects on the voltage sensor, although both affect the $\mathrm{Ca}^{2+}$ binding affinity and the allosteric coupling between sensors, and sensors and gate (Cox and Aldrich, 2000; Orio and Latorre, 2005; Yang et al., 2008).

Previous studies have identified the $\mathrm{N}$ terminus, S0 segment, and voltage-sensing residues in Slo1 that play important roles for the function of the $\beta 1$ subunit (Wallner et al., 1996; Morrow et al., 2006; Yang et al., 2008). However, the structural components in Slo1 that are important for the function of the $\beta 2$ subunit are not known. In this study, we take advantage of differential effects of the $\beta 2$ subunit on two BK channel orthologs to make chimeras between them and test which structural component confers the properties of its parent channel in response to the modulation by the $\beta 2$ subunit. These experiments identified two regions of the Slo1 subunit that are critical for the $\beta 2$-dependent increase of $\mathrm{Ca}^{2+}$ sensitivity. The first region contains the extracellular N terminus and $\mathrm{S} 0$ segment. The second region, which is specifically important for the $\beta 2$-dependent increase of $\mathrm{Ca}^{2+}$ sensitivity, contains the linker connecting S6 and the cytoplasmic domain, the $\mathrm{C}$-Linker, and the $\mathrm{N}$ terminus of RCK1, the AC region ( $\beta \mathrm{A}-$ $\alpha \mathrm{C}$ ) (Fig. 1). This segment has been shown previously to mediate the allosteric coupling between $\mathrm{Ca}^{2+}$ binding and the opening 

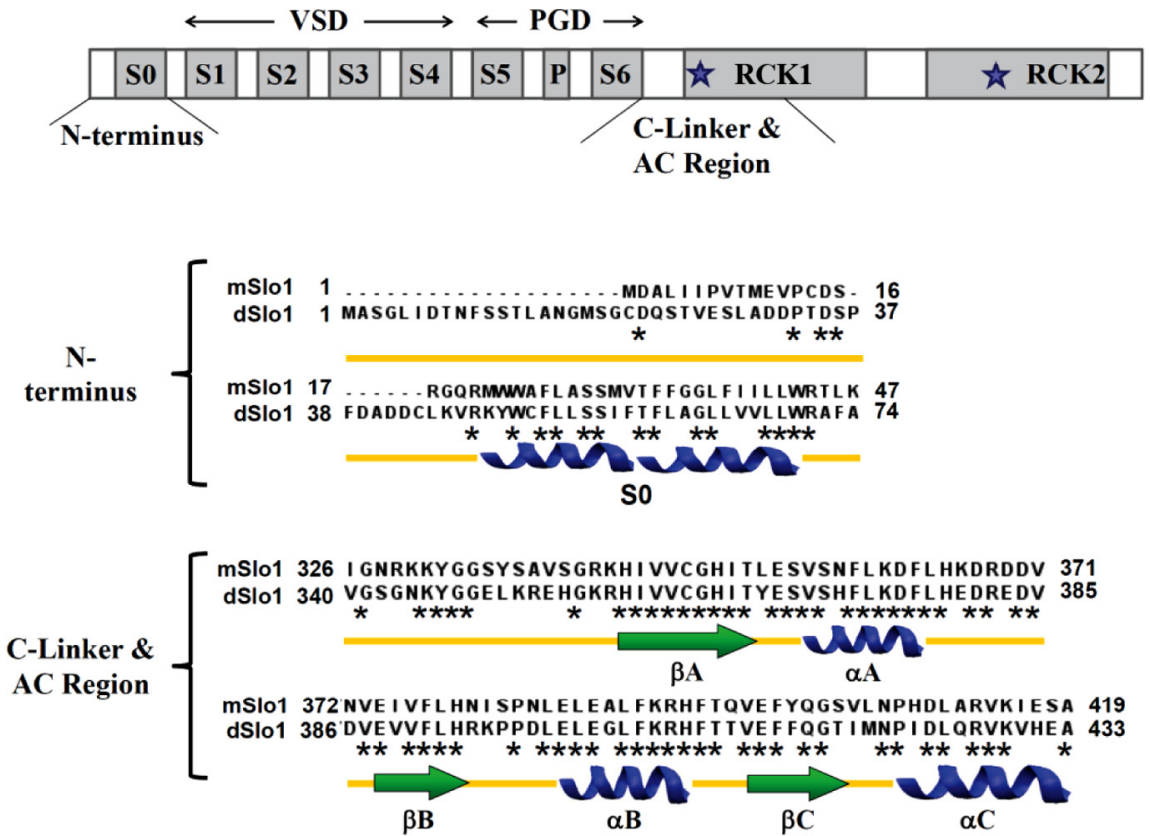

Figure 1. Schematic of BK channel structure. Top, $\mathrm{SO}-\mathrm{S} 6$ are transmembrane segments, and RCK1 and RCK2 are located in cytoplasm. PGD, Pore-gate domain. $\operatorname{Star}(\star)$ represents the location of $\mathrm{Ca}^{2+}$ binding sites. The sequence and secondary structure of the $\mathrm{N}$ terminus including $\mathrm{S} 0$ and the $\left(-\right.$ Linker and $\mathrm{AC}$ region are shown below. Asterisk $\left(^{*}\right)$ identifies conserved residues.

Table 1. Residue information of mSlo1- dSlo1 chimeras

\begin{tabular}{lcc}
\hline & \multicolumn{2}{l}{ Residues from } \\
\cline { 2 - 3 } Chimera name & $d S 101$ & $\mathrm{mSl} 1$ \\
\hline $\mathrm{C} 1$ & $1-596$ & $580-1169$ \\
$\mathrm{C} 2$ & $1-336$ & $323-1169$ \\
$\mathrm{C} 3$ & $1-248$ & $234-1169$ \\
$\mathrm{C} 4$ & $1-215$ & $201-1169$ \\
$\mathrm{C} 5$ & $1-147$ & $134-1169$ \\
$\mathrm{~m}[\mathrm{dSO} 0]$ & $1-70$ & $44-1169$ \\
$\mathrm{~m}[\mathrm{dLinker}+\mathrm{dAC}]$ & $340-432$ & $1-325$ and $419-1169$ \\
$\mathrm{~m}[\mathrm{dSO}+\mathrm{dLinker}+\mathrm{dAC}]$ & $1-70$ and $340-432$ & $44-325$ and $419-1169$ \\
$\mathrm{~d}[\mathrm{mSO}]$ & $71-1164$ & $1-43$ \\
$\mathrm{~d}[\mathrm{~mL}$ inker $+\mathrm{mAC}]$ & $1-339$ and $433-1164$ & $326-418$ \\
$\mathrm{~d}[\mathrm{mSO}+\mathrm{mLinker}+\mathrm{mRCK1C}]$ & $71-346$ and $559-1164$ & $1-43$ and $320-543$ \\
\hline
\end{tabular}

of the activation gate (Niu et al., 2004; Krishnamoorthy et al., 2005; Yang et al., 2010). Our results in this study support the role of this segment in $\mathrm{Ca}^{2+}$-dependent activation of BK channels and suggest that the $\beta 2$ subunit enhances the allosteric coupling between $\mathrm{Ca}^{2+}$ binding and the opening of the activation gate.

\section{Materials and Methods}

Mutagenesis and expression. All chimeras and point mutations were generated from the $m b r 5$ splice variant of mouse Slo1 (mSlo1) (Butler et al., 1993) and the A1C2E1G3I0 splice variant of Drosophila Slo1 (dSlo1) (Adelman et al., 1992) in the pBSC-MXT vector. The protein sequences of $\mathrm{mSlo} 1$ and dSlo1 used in the design of each chimera are shown in Table 1. Human $\beta 1$ and $\beta 2$ (KCNMB1 and KCNMB2; GenBank accession numbers U25138 and AF209747, respectively) cDNAs were subcloned into pcDNA3.1 $(+)$. The $\beta 2 \mathrm{~N}$ terminus-deleted ( $\beta 2 \mathrm{ND}$ ) subunit was created by removing amino acids from positions 2 through 20 . All chimeras and mutations were made using overlap-extension PCR (Shi et al., 2002) with $P f u$ polymerase (Stratagene). The PCR-amplified regions for all constructs were verified by sequencing. cRNA was transcribed in vitro using T3 polymerase (Ambion) for all Slo1 constructs and T7 polymerase (Ambion) for $\beta 1$ and $\beta 2 \mathrm{ND}$ subunits. A total of $0.05-20 \mathrm{ng}$ of Slo1 cRNA or a mixture of 5-15 ng of Slo1 and 25-50 ng of $\beta$ subunit cRNAs were injected into each Xenopus laevis oocyte. Oocytes were incubated in
ND96 solution (in mu: $96 \mathrm{NaCl}, 2 \mathrm{KCl}, 1.8$ $\mathrm{CaCl}_{2}, 1 \mathrm{MgCl}_{2}$, and 5 HEPES, pH 7.6) at $18^{\circ} \mathrm{C}$ for 3-6 d before recording.

Electrophysiology. Macroscopic currents were recorded from inside-out patches formed with borosilicate pipettes of $\sim 0.9-1.5 \mathrm{M} \Omega$ resistance. The data were acquired using an Axopatch 200-B patch-clamp amplifier (Molecular Devices) and Pulse acquisition software (HEKA). Recordings were digitized at $20 \mu \mathrm{s}$ intervals and low-pass filtered at $10 \mathrm{kHz}$ with the four-pole Bessel filter built in the amplifier. Capacitive transients and leak currents were subtracted using a $\mathrm{P} / 5$ protocol. Experiments were conducted at room temperature $\left(20-22^{\circ} \mathrm{C}\right)$. The pipette solution contained the following (in mM): $140 \mathrm{KMeSO}_{3}, 20 \mathrm{HEPES}, 2$ $\mathrm{KCl}$, and $2 \mathrm{MgCl}_{2}, \mathrm{pH}$ 7.2. The internal solution contained the following (in $\mathrm{mM}$ ): 140 $\mathrm{KMeSO}_{3}, 20 \mathrm{HEPES}, 2 \mathrm{KCl}$, and $1 \mathrm{~N}$-(2hydroxyethyl) ethylenediamine- $\mathrm{N}, \mathrm{N}, \mathrm{N}$-triacetic acid (HEDTA), pH 7.2. $\mathrm{CaCl}_{2}$ was added to the internal solution to give the appropriate free $\left[\mathrm{Ca}^{2+}\right]_{\mathrm{i}}$, which was measured with a calciumsensitive electrode (Orion Research). 18-Crown6-tetracarboylic acid (50 $\mu \mathrm{m}$; Sigma-Aldrich) was added to internal solutions to chelate $\mathrm{Ba}^{2+}$. For nominal $0 \mu \mathrm{M}\left[\mathrm{Ca}^{2+}\right]_{\mathrm{i}}$, the same internal solution was used except that HEDTA was substituted by $5 \mathrm{~mm}$ EGTA and no $\mathrm{CaCl}_{2}$ was added. The free $\left[\mathrm{Ca}^{2+}\right]$ in nominal $0 \mu \mathrm{M}\left[\mathrm{Ca}^{2+}\right]_{\mathrm{i}}$ solution is $0.5 \mathrm{~nm}$. Experiments were conducted over a period of time in which multiple different $\left[\mathrm{Ca}^{2+}\right]_{\mathrm{i}}$ were made and their concentrations varied. For the sake of simplicity, the $2 \mu \mathrm{M} \mathrm{Ca}{ }^{2+}$ is referred to as $\sim 2 \mu \mathrm{M}$ when the concentration varied from 1.8 to $2.3 \mu \mathrm{M}$, and the saturating $\left[\mathrm{Ca}^{2+}\right]_{\mathrm{i}}$ is referred to as $\sim 100 \mu \mathrm{M}$ when the concentration varied from 87.1 and $118.4 \mu \mathrm{M}$.

Data analysis. The relative conductance was determined by measuring tail current amplitudes at indicated voltages for all channels with and without $\beta$ subunits. The conductance-voltage ( $G-V$ ) relationships for all channels with and without $\beta$ subunits were fitted with the Boltzmann equation: $\frac{G}{G_{\max }}=\frac{1}{1+e^{-z e\left(V-V_{1 / 2}\right)} / k T}$, where $G / G_{\max }$ is the ratio of conductance to maximum conductance in the same $\left[\mathrm{Ca}^{2+}\right]_{\mathrm{i}}, z$ is the number of equivalent charges, $V_{1 / 2}$ is the voltage at which the channel is $50 \%$ activated, $e$ is the elementary charge, $k$ is Boltzmann's constant, and $T$ is the absolute temperature. Curve fittings were done with Igor Pro software (WaveMetrics) using the Levenberg-Marquardt algorithm to perform nonlinear least-squares fits. Statistics were performed using Origin 6.1 (OriginLab Corp.), and independent/unpaired $t$ test was performed. A $p$ value of $<0.05$ was considered significant.

Monod-Wyman-Changeux model. Monod-Wyman-Changeux (MWC) model fits were performed using the following equation:

$$
P_{\text {open }}=\frac{1}{1+L_{0} \cdot e^{\frac{-z e V}{k T}} \cdot\left[\frac{1+\frac{\left[\mathrm{Ca}^{2+}\right]}{K_{\mathrm{C}}}}{1+\frac{\left[\mathrm{Ca}^{2+}\right]}{K_{\mathrm{O}}}}\right]^{4}},
$$

where $P_{\text {open }}$ is the open probability of the channel, $L_{0}$ is the steady-state equilibrium constant from open to closed channels $\left(\left[\mathrm{C}_{0}\right] /\left[\mathrm{O}_{0}\right]\right)$ in the absence of $\mathrm{Ca}^{2+}$ binding at $0 \mathrm{mV}, z, e, k$, and $T$ are same as in the Boltzmann equation (see above), and $K_{\mathrm{C}}$ and $K_{\mathrm{O}}$ are the dissociation constants of $\mathrm{Ca}^{2+}$ in the closed and open states, respectively. MWC model code was written and executed in MATLAB version 7.4 (MathWorks).

Because BK channels are activated by both voltage and $\mathrm{Ca}^{2+}$, the ideal condition for measuring $\mathrm{Ca}^{2+}$ sensitivity of channel activation would be 
A
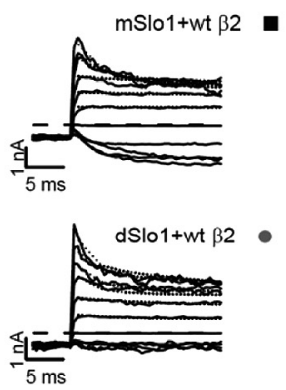

B
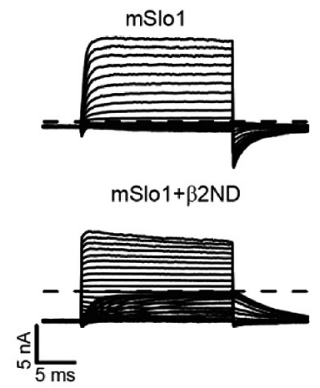

C
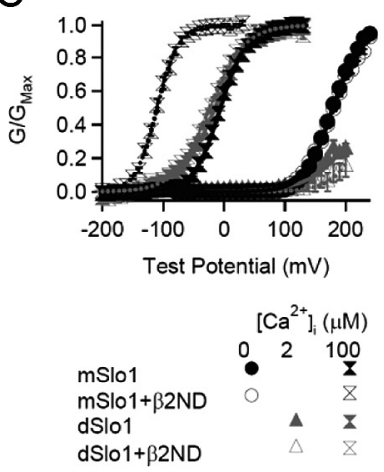

Figure 2. Differential modulation by $\beta 2 \mathrm{ND}$ on $\mathrm{Ca}^{2+}$ sensitivity of mSlo1 and dSlo1. $\boldsymbol{A}$, Macroscopic currents of mSlo1 and dSlo1 with WT h $\beta 2$ at $\sim 100 \mu \mathrm{m}\left[\mathrm{Ca}^{2+}\right]_{\mathrm{i}}$ (left). The voltage pulses are from -100 to $+150 \mathrm{mV}$ for $1 \mathrm{~s}$ with $25 \mathrm{mV}$ increments (shown only the first $20 \mathrm{~ms}$ ), and the prepulse potential is $-140 \mathrm{mV}$ for $195 \mathrm{~ms}$ (shown only the last $5 \mathrm{~ms}$ ). The dotted line represents the biexponential fit of the inactivation profile, and the long dashed line represents the zero current line for each current trace. On the right, voltage dependence of the inactivation time constant is shown. The fast and slow components of $\tau_{\text {Inact }}$ were obtained by fitting current traces with a biexponential function from the peak amplitude to steady state $(n=10$ for $\mathrm{mSl} 01+$ WT $\beta 2$, except at $+150 \mathrm{mV}, n=9 ; n=5$ for dSlo $1+$ WT $\beta 2$, except at $+150 \mathrm{mV}, n=4)$. $\boldsymbol{B}$, Macroscopic currents of mSlo1 and dSlo1 with and without $\beta 2 \mathrm{ND}$ at $\sim 100 \mu \mathrm{m}\left[\mathrm{Ca}^{2+}\right]_{\mathrm{i}}$. Voltage pulses are from - 200 to $100 \mathrm{mV}$ with $10 \mathrm{mV}$ increments, and the repolarizing potential is $-50 \mathrm{mV}$, except for $\mathrm{mSl} 01+\beta 2 \mathrm{ND}$, which is $-80 \mathrm{mV}$. The dashed line represents the zero current line for each current trace. $C$, Mean $\mathrm{G}-V$ relationship of $\mathrm{mSl} 01 / \mathrm{dSl} 01$ with and without $\beta 2 \mathrm{ND}$ in $0, \sim 2$, and $\sim 100 \mu \mathrm{m}\left[\mathrm{Ca}^{2+}\right]_{\mathrm{i}}$, fitted with Boltzmann equation (smooth lines). The error bars in this and other figures show the SEM. $D, V_{1 / 2}$ versus $\left[\mathrm{Ca}^{2+}\right]_{i}$ plot of $\mathrm{mSl} 01 / \mathrm{dSl} 01$ with and without $\beta 2 \mathrm{ND}$. The number of patches for each dataset are for the following $(\mu \mathrm{m})$ : $\left[\mathrm{Ca}^{2+}\right]_{\mathrm{i}}, 0,1,2,5,10,30,100 ; \mathrm{mSl} 1,118,33,29,29,42,25,56 ; \mathrm{mSl} 1+\beta 2 \mathrm{ND}, 44,8,8,11$, 9, 12, 28; dSlo1, 0, 0, 11, 19, 15, 9, 27; dSlo1 + $\beta 2 \mathrm{ND}, 0,0,3,4,7,8,14$

in the absence of voltage sensor movements. Such measurements have been done at very negative voltages (less than $-130 \mathrm{mV}$ ) at which the voltage sensor of BK channels is kept at the resting state (Horrigan and Aldrich, 2002). $\mathrm{Ca}^{2+}$-dependent activation of BK channels under such a condition could be fitted by the MWC model, and the results show that the parameters $K_{\mathrm{C}}$ and $K_{\mathrm{O}}$ have very similar values as those obtained by the MWC model fitting to the $G-V$ relations (Cox et al., 1997; Horrigan and Aldrich, 2002; Sweet and Cox, 2008; Yang et al., 2010), which is the method we used in this study. The lack of a large influence of voltage on $\mathrm{Ca}^{2+}$ affinity measurement is not surprising because it has been shown
Table 2. Parameters for MWC model fits

\begin{tabular}{lllrrr}
\hline & \multicolumn{1}{c}{$L_{0}$} & $z$ & $K_{\mathrm{C}}(\mu \mathrm{m})$ & $K_{0}(\mu \mathrm{m})$ & $1 / \mathrm{c}$ \\
\hline $\mathrm{mSl01}$ & $9.20 \mathrm{E}+03$ & 1.28 & 7.36 & 0.72 & 10.25 \\
$\mathrm{mSl01}+\beta 2 \mathrm{ND}$ & $9.41 \mathrm{E}+03$ & 1.25 & 32.51 & 0.62 & 52.35 \\
$\mathrm{dSl01}$ & $5.50 \mathrm{E}+05$ & 0.88 & 22.00 & 0.51 & 43.48 \\
$\mathrm{dSl01}+\beta 2 \mathrm{ND}$ & $5.51 \mathrm{E}+05$ & 0.78 & 23.95 & 0.53 & 45.28 \\
$\mathrm{~m}[\mathrm{dSO}+\mathrm{dLinker}+\mathrm{dAC}]$ & $9.98 \mathrm{E}+05$ & 1.12 & 12.36 & 0.40 & 30.60 \\
$\mathrm{~m}[\mathrm{dSO}+\mathrm{dLinker}+\mathrm{dAC}]+\beta 2 \mathrm{ND}$ & $9.80 \mathrm{E}+05$ & 1.02 & 9.45 & 0.36 & 26.18 \\
$\mathrm{~d}[\mathrm{mSO}+\mathrm{mLinker}+\mathrm{mRCK1C}]$ & $3.50 \mathrm{E}+04$ & 1.07 & 30.76 & 3.30 & 9.32 \\
$\mathrm{~d}[\mathrm{mSO}+\mathrm{mLinker}+\mathrm{mRCK1c}]+\beta 2 \mathrm{ND}$ & $7.90 \mathrm{E}+03$ & 1.08 & 71.00 & 2.45 & 28.98 \\
\hline & & & & &
\end{tabular}

that voltage and $\mathrm{Ca}^{2+}$ activate the channel through distinct mechanisms that have little interaction (Cui and Aldrich, 2000; Horrigan and Aldrich, 2002; Sweet and Cox, 2008). In the MWC model used in this study, each Slo1 subunit is assumed to contain a single $\mathrm{Ca}^{2+}$ binding site, although previous studies have proposed two putative $\mathrm{Ca}^{2+}$ binding sites in each Slo1 subunit (Schreiber and Salkoff, 1997; Xia et al., 2002). A model composed of two $\mathrm{Ca}^{2+}$ binding sites would not provide any additional information because we are interested in the effect on the overall $\mathrm{Ca}^{2+}$ sensitivity of the BK channel. Despite this simplification, the MWC model used in this study provides an appropriate account of the $\mathrm{Ca}^{2+}$ sensitivity changes in BK channels.

\section{Results}

The $\beta 2 \mathrm{ND}$ subunit modulates $\mathrm{Ca}^{2+}$ sensitivity of $\mathrm{mSlol}$ and dSlo1 differently

Besides increasing $\mathrm{Ca}^{2+}$ sensitivity of mSlol channels, the $\beta 2$ subunit also inactivates the channel by a "ball and chain" mechanism such that the $\mathrm{N}$ terminus of the $\beta 2$ subunit blocks the open channel (Ding et al., 1998; Hicks and Marrion, 1998; Wallner et al., 1999; Xia et al., 1999, 2003) (Fig. 2A). To study increases in $\mathrm{Ca}^{2+}$ sensitivity conferred by the $\beta 2$ subunit in the absence of inactivation, we deleted the amino acids $2-20$ of the human $\beta 2$ subunit, which resulted in the $\beta 2 \mathrm{ND}$ subunit that no longer causes inactivation (Fig. 2 B) (Wallner et al., 1999; Xia et al., 1999, 2003; Brenner et al., 2000). We coexpressed the $\beta 2$ ND subunit with mSlol and dSlo1 and observed the changes to their properties the (Fig. 2). The association of $\beta 2 \mathrm{ND}$ increases the rate of activation of mSlo1 (Brenner et al., 2000; Orio and Latorre, 2005; Orio et al., 2006; Lee and Cui, 2009) and decreases the rate of deactivation of both $\mathrm{mSlo} 1$ and dSlo1 (Fig. $2 B$ ). Because the association of $\beta 2 \mathrm{ND}$ with $\mathrm{mSlol}$ shifts the $G-V$ relation to more negative voltages, the deactivation time course was measured at a more negative voltage with $\beta 2 \mathrm{ND}$ than without $\beta 2 \mathrm{ND}$. However, mSlo1 with $\beta 2 \mathrm{ND}$ still deactivates more slowly than mSlo1 alone $\left(\tau_{\text {Dact }}, 5.7 \pm 0.3 \mathrm{~ms}\right.$ at $-120 \mathrm{mV}$ and $1.8 \pm 0.1 \mathrm{~ms}$ at $-50 \mathrm{mV}$, respectively when prepulsed to $+100 \mathrm{mV}, p<0.001$ with $n=14$ and 55, respectively). Measured at the same voltage, dSlo1 with $\beta 2 \mathrm{ND}$ also deactivates significantly more slowly than dSlo1 alone $\left(\tau_{\text {Dact }}, 1.5 \pm 0.2\right.$ and $0.8 \pm 0.1 \mathrm{~ms}$ at $-50 \mathrm{mV}$, respectively, when prepulsed to $+200 \mathrm{mV}, p<0.001$ with $n=7$ and 23 , respectively). These changes in the macroscopic currents indicate a physical association between the $\beta 2 \mathrm{ND}$ subunit and Slol orthologs. Coexpression of the wild-type (WT) $\beta 2$ subunit with both $\mathrm{mSlo} 1$ and dSlol confer inactivation in the channels (Fig. $2 A$ ), further indicating that the $\beta 2$ subunits associate with both Slo1 orthologs. However, the $\beta 2 \mathrm{ND}$ subunit has different effects on the $\mathrm{Ca}^{2+}$-dependent activation of the two Slol orthologs. The association of the $\beta 2 \mathrm{ND}$ subunit shifts the $G-V$ relation of mSlo1 channels to more negative potentials by $\sim 100 \mathrm{mV}$ at the saturating $\left[\mathrm{Ca}^{2+}\right]_{\mathrm{i}}$ of $\sim 100 \mu \mathrm{M}$ but has little effect on the $G-V$ of dSlo1 channels $\left(V_{1 / 2}\right.$ of dSlo1, $-19.3 \pm 2.5 \mathrm{mV}$ and $V_{1 / 2} \mathrm{dSlo} 1+\beta 2 \mathrm{ND}$, $-23.8 \pm 2.7 \mathrm{mV}, p>0.05 ; V^{1 / 2}$ is the voltage at which the $G-V$ 

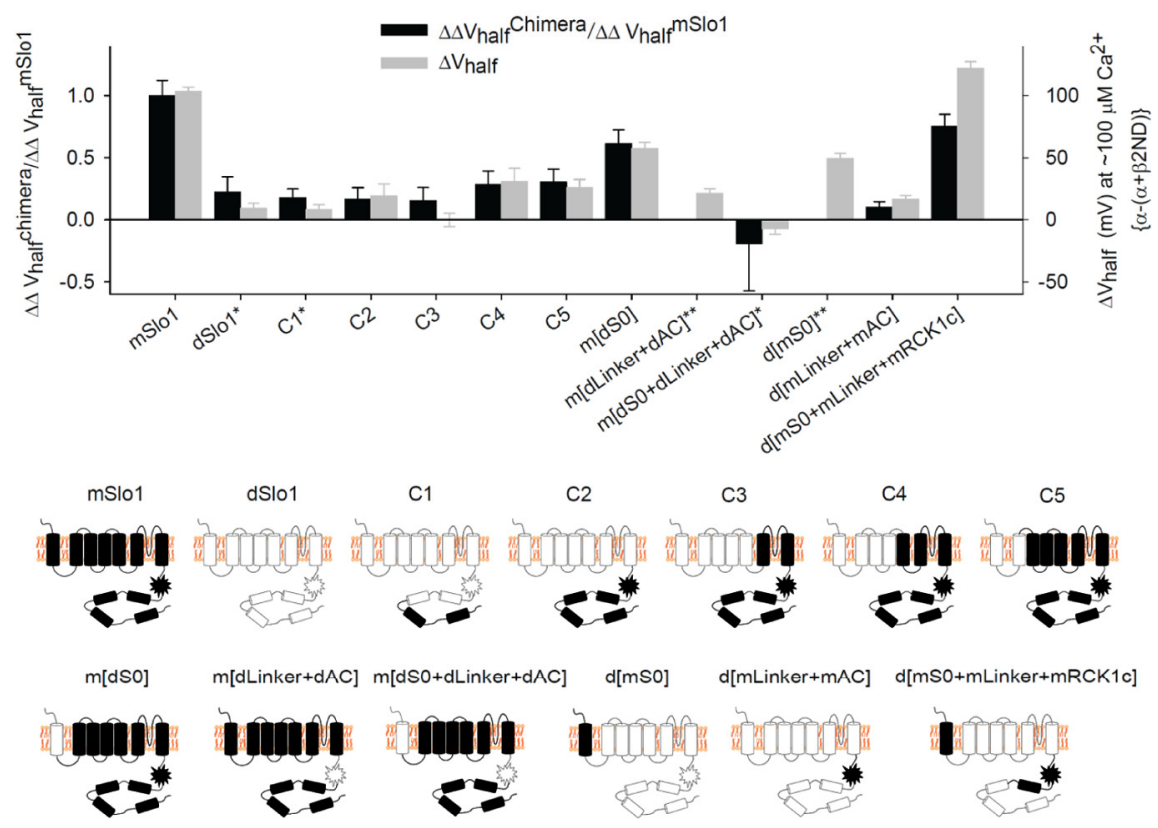

Figure 3. Effects of chimeras of $\mathrm{mSl} 1 / \mathrm{dSl} 1$ on the $\beta 2 \mathrm{ND}$ modulation of $\mathrm{Ca}^{2+}$ dependence. The black bars show the change in $\mathrm{Ca}^{2+}$ sensitivity between with and without $\beta 2 \mathrm{ND}$, normalized to $\mathrm{mSl} 101$ (see Results for definitions). The gray bars show the $\mathrm{Ca}^{2+}$ response at $\sim 100 \mu \mathrm{m}\left[\mathrm{Ca}^{2+}\right]_{\mathrm{i}}$ between with and without $\beta 2 \mathrm{ND}$. The symbol ${ }^{*}$ means that $\sim 2 \mu \mathrm{m}\left[\mathrm{Ca}^{2+}\right]_{\mathrm{i}}$ was used for comparison, and ${ }^{* *}$ means that the $G-V$ could not be determined at 0 or $\sim 2 \mu \mathrm{m}\left[\mathrm{Ca}^{2+}\right]_{\mathrm{i}}$. Bottom shows the schematic of different chimeras of $\mathrm{mSI} 101$ and dSlo 1 used in the top. The number of patches for each dataset are as follows for either $\sim 0 / 2$ and $100 \mu \mathrm{m}\left[\mathrm{Ca}^{2+}\right]_{\mathrm{i}} \mathrm{C} 1,3,5 ; \mathrm{C} 1+\beta 2 \mathrm{ND}, 9,11 ; \mathrm{C}, 4$, $3 ; C 2+\beta 2 \mathrm{ND}, 5,4 ; C 3,7,4 ; C 3+\beta 2 \mathrm{ND}, 5,5 ; C 4,5,5 ; C 4+\beta 2 \mathrm{ND}, 8,3 ; C 5,7,5 ; C 5+\beta 2 \mathrm{ND}, 3,4 ; \mathrm{m}[\mathrm{dSO} 0]: 9,6 ; \mathrm{m}[\mathrm{dSO}]+\beta 2 \mathrm{ND}, 4,7 ;$ $\mathrm{m}[\mathrm{dLinker}+\mathrm{dAC}], 7,20 ; \mathrm{m}[\mathrm{dL}$ inker $+\mathrm{dAC}]+\beta 2 \mathrm{ND}, 0,20 ; \mathrm{m}[\mathrm{dSO}+\mathrm{dLinker}+\mathrm{dAC}], 5,14 ; \mathrm{m}[\mathrm{dSO}+\mathrm{dLinker}+\mathrm{dAC}]+\beta 2 \mathrm{ND}: 2,9 ;$ $d[m S 0], 3,20 ; d] m S O]+\beta 2 N D, 0,12 ; d[m L i n k e r+m A C], 13,7 ; d[m L i n k e r+m A C]+\beta 2 N D, 23,13 ; d[m S 0+m L i n k e r+m R C K 1 c], 11$, $16 ; \mathrm{d}[\mathrm{mSO}+\mathrm{mLinker}+\mathrm{mRCK1c}]+\beta 2 \mathrm{ND}, 15,14$.

relation is half-maximum) (Fig. $2 C$ ). At nominal $0\left[\mathrm{Ca}^{2+}\right]_{\mathrm{i}}$, the $\beta 2 \mathrm{ND}$ association does not alter the $G-V$ relation of the mSlo1 channels $\left(V_{1 / 2}\right.$ of mSlo1, $178.3 \pm 1.1 \mathrm{mV}$ and $V_{1 / 2} \mathrm{mSlo} 1+\beta 2 \mathrm{ND}$, $181.9 \pm 1.8 \mathrm{mV}, p>0.05$ ) (Fig. $2 C$ ) (Orio and Latorre, 2005), indicating that $\beta 2 \mathrm{ND}$ modulates $\mathrm{Ca}^{2+}$-dependent activation of mSlo1. In contrast, the association of $\beta 2 \mathrm{ND}$ with dSlo1 has no significant effect at any $\left[\mathrm{Ca}^{2+}\right]_{\mathrm{i}}$ tested in our study. For instance, at $\sim 2 \mu \mathrm{M} \mathrm{Ca}^{2+}{ }_{\mathrm{i}}, V_{1 / 2}$ of dSlo1 and dSlo1 $+\beta 2 \mathrm{ND}$ is $243.4 \pm 6.5$ and $241.5 \pm 5.2 \mathrm{mV}$, respectively $(p>0.05)$ (Fig. $2 C$ ). The plot of $V_{1 / 2}$ versus $\left[\mathrm{Ca}^{2+}\right]_{\mathrm{i}}$ shows that the association of the $\beta 2 \mathrm{ND}$ subunit results in a gradual increase in the negative shift of the mSlo1 $G-V$ relation with increasing $\left[\mathrm{Ca}^{2+}\right]_{\mathrm{i}}$ but no shift of the dSlo1 $G-V$ relation (Fig. $2 D$ ). In $\left[\mathrm{Ca}^{2+}\right]_{\mathrm{i}} \leq 1 \mu \mathrm{M}$, few dSlo1 channels activate at voltages within the experimental limit (up to +300 $\mathrm{mV}$ ) so that the $G-V$ relations cannot be determined in these $\left[\mathrm{Ca}^{2+}\right]_{\mathrm{i}}$. The results in Figure 2 clearly show that the $\beta 2 \mathrm{ND}$ subunit modulates $\mathrm{Ca}^{2+}$-dependent activation of mSlo1 but not dSlo1.

To further illustrate the differences in $\mathrm{Ca}^{2+}$ sensitivity imparted by $\beta 2 \mathrm{ND}$ on mSlo1 and dSlo1 channels, a voltagedependent MWC model (Cox et al., 1997) was used to fit the $G-V$ relations at different $\left[\mathrm{Ca}^{2+}\right]_{\mathrm{i}}$ (see Fig. 6; Table 2). In mSlo1 channels, the association of $\beta 2 \mathrm{ND}$ subunit increases the dissociation constant for $\mathrm{Ca}^{2+}$ binding in the closed state $\left(K_{\mathrm{C}}\right)$ by $>300 \%$ and decreases the dissociation constant in the open state $\left(K_{\mathrm{O}}\right)$ by $14 \%$ (Table 2), same as reported previously (Orio and Latorre, 2005). Because of the disproportional change in the two dissociation constants, the ratio $c=K_{\mathrm{O}} / K_{\mathrm{C}}$ is smaller in mSlo1 $+\beta 2 \mathrm{ND}$ than in mSlo1 channels, which indicates that $\mathrm{Ca}^{2+}$ favors the open state in the closed-open equilibrium more with the association of $\beta 2 \mathrm{ND}$ (Table 2) (Cox et al., 1997). The association of $\beta 2 \mathrm{ND}$ does not alter voltage dependence of mSlo1 channels, which is reflected in similar values of the parameters $z$ and $L_{0}$, where $z$ is the number of gating charges in the voltage sensor of the channels, and $L_{0}$ is the equilibrium constant of channel from the open to the closed state at $0 \mathrm{mV}$ and in the absence of $\mathrm{Ca}^{2+}$ (Table 2). In dSlo1 channels, the association of $\beta 2 \mathrm{ND}$ does not change $K_{\mathrm{C}}, K_{\mathrm{O}}$, or voltage dependence (Table 2). Collectively, these results show that the $\beta 2 \mathrm{ND}$ subunit specifically enhances $\mathrm{Ca}^{2+}$ sensitivity in mSlol channels but results in no such changes in dSlo1 channels, although $\beta 2 \mathrm{ND}$ is associated with dSlo1 subunit.

The $\mathrm{N}$ termini of the transmembrane and cytoplasmic domains of mSlol and dSlo1 are necessary and sufficient to account for the different effects of the $\beta 2 N D$ subunit

Taking advantage of the differences in the response of the Slo1 orthologs to $\beta 2 \mathrm{ND}$ modulation, a chimera strategy to exchange the secondary structural regions between mSlo1 and dSlo1 subunits was devised to find the structural components responsible for the $\beta 2$-dependent enhancement of $\mathrm{Ca}^{2+}$ sensitivity. To examine whether the association of $\beta 2 \mathrm{ND}$ alters $\mathrm{Ca}^{2+}$ sensitivity of a channel, two criteria were used. First, $\mathrm{Ca}^{2+}$ sensitivity of a channel was estimated by the shift of its $G-V$ relation in $\sim 100 \mu \mathrm{M}\left[\mathrm{Ca}^{2+}\right]_{\mathrm{i}}$ in response to the association of $\beta 2 \mathrm{ND}, \Delta V_{\text {half }}=V_{1 / 2(100 \mathrm{Ca}) \text { with }}$

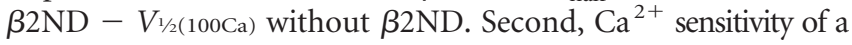

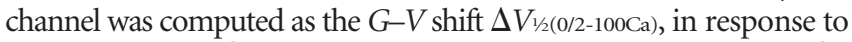
an increase of $\left[\mathrm{Ca}^{2+}\right]_{\mathrm{i}}$ from 0 or $\sim 2$ to $\sim 100 \mu \mathrm{M}$, the change in $\mathrm{Ca}^{2+}$ sensitivity resulted from the association of $\beta 2 \mathrm{ND}$ was $\Delta \Delta V_{\text {half }}=$ $\Delta V_{1 / 2(0 / 2-100 \mathrm{Ca})}$ with $\beta 2 \mathrm{ND}-\Delta V_{1 / 2(0 / 2-100 \mathrm{Ca})}$ without $\beta 2 \mathrm{ND}$, which was then normalized to $\Delta \Delta V_{\text {half }}$ of the WT mSlo1 obtained under the same condition (Fig. 3). Using these two criteria, mSlo1 exhibited greater modulation by the association of $\beta 2 \mathrm{ND}$ than dSlo1 (Fig. 3).

The chimeras developed for this study are shown in the bottom of Figure 3, where the initial designs (chimeras $\mathrm{C} 1$ through $\mathrm{m}[\mathrm{dSO}]$ ) were composed of dSlo1 channels with increasing mSlo1 regions substituting the dSlo1 counterparts. In chimeras $\mathrm{C} 1-\mathrm{C} 5$, the addition of mSlo1 regions did not confer $\beta 2 \mathrm{ND}$ modulation; rather, the $\mathrm{Ca}^{2+}$ sensitivity of these channels and their responses to the association of $\beta 2 \mathrm{ND}$ were similar to that of dSlo 1 (Fig. 3). Even the chimera containing only the $\mathrm{N}$ terminus of dSlo1, including the transmembrane segment S0 (m[dSO]), shows an $\sim 40 \%$ reduced response to the $\beta 2 \mathrm{ND}$ modulation, indicating that the $\mathrm{N}$ terminus of mSlol is important for the $\beta 2 \mathrm{ND}$ modulation of $\mathrm{Ca}^{2+}$ sensitivity (Fig. 3). The result of $\mathrm{m}[\mathrm{dSO}]$ in Figure 3 is computed from the current measurements and $G-V$ relations shown in Figure 4, $A$ and $B$. Figure $4 C$ shows additional studies of the $\mathrm{Ca}^{2+}$ sensitivity of this chimera where the $V_{1 / 2}$ of $G-V$ relations of the channel with (black unfilled circles) and without (black filled circles) $\beta 2 \mathrm{ND}$ in various $\left[\mathrm{Ca}^{2+}\right]_{\mathrm{i}}$ from nominal 0 to saturating $\sim 100 \mu \mathrm{M}$ are plotted versus $\left[\mathrm{Ca}^{2+}\right]_{\mathrm{i}}$. For comparison, similar data from dSlo1 (blue dotted 
and solid lines) and mSlo1 (orange dotted and solid lines) are also shown (Fig. 4C). The $\beta 2 \mathrm{ND}$ subunit enhances $\mathrm{Ca}^{2+}$ sensitivity of mSlo1 channels and gradually shifts its $G-V$ relation as $\left[\mathrm{Ca}^{2+}\right]_{\mathrm{i}}$ increases (Fig. 2) so that the $V_{1 / 2}-\left[\mathrm{Ca}^{2+}\right]_{i}$ relations of mSlo1 channels with and without $\beta 2 \mathrm{ND}$ bifurcate (Fig. $4 C$, orange). On the contrary, the $\beta 2 \mathrm{ND}$ subunit does not alter $\mathrm{Ca}^{2+}$ sensitivity of dSlo1 channels so that the $V_{1 / 2}-\left[\mathrm{Ca}^{2+}\right]_{\mathrm{i}}$ relations of dSlo1 channels with and without $\beta 2 \mathrm{ND}$ superimpose (Fig. $4 C$, blue). Although the $V_{1 / 2}-\left[\mathrm{Ca}^{2+}\right]_{\mathrm{i}}$ relations of $\mathrm{m}[\mathrm{dSO}]$ with and without $\beta 2 \mathrm{ND}$ bifurcate (Fig. $4 C$, black), the difference between the two curves is smaller than that of mSlo1 at all nonzero $\left[\mathrm{Ca}^{2+}\right]_{\mathrm{i}}$, clearly showing that the $\mathrm{N}$ terminus of mSlol is important for the $\beta 2 \mathrm{ND}$-dependent enhancement of $\mathrm{Ca}^{2+}$ sensitivity.

To examine whether the $\mathrm{N}$ terminus of $\mathrm{mSlo} 1$ alone is responsible for the $\beta 2 \mathrm{ND}$ dependent enhancement of $\mathrm{Ca}^{2+}$ sensitivity, we made the converse chimera of $\mathrm{m}$ [dSO], $\mathrm{d}[\mathrm{mSO}]$, in which the $\mathrm{N}$ terminus to the end of $\mathrm{S} 0$ of mSlo1 is transplanted into dSlo1. Because few $\mathrm{d}[\mathrm{mSO}]$ channels open in $\left[\mathrm{Ca}^{2+}\right]_{\mathrm{i}}<\sim 2 \mu \mathrm{M}$ (Fig. $5 \mathrm{~A}, \mathrm{~B}$ ), the change of $\mathrm{Ca}^{2+}$ sensitivity attributable to the association of $\beta 2 \mathrm{ND}$ is only estimated by $\Delta V_{\text {half }}$ in Figure 3 , which suggests that the $\mathrm{N}$ terminus of mSlo1 is not sufficient to render dSlol the same response to $\beta 2 \mathrm{ND}$ as mSlo1. Additional studies of $\mathrm{Ca}^{2+}$ sensitivity of this chimera in various $\left[\mathrm{Ca}^{2+}\right]_{\mathrm{i}}$ show that the $\mathrm{V}_{1 / 2}-\left[\mathrm{Ca}^{2+}\right]_{\mathrm{i}}$ relations of $\mathrm{d}[\mathrm{mSO}]$ with and without $\beta 2 \mathrm{ND}$ only bifurcate at high $\left[\mathrm{Ca}^{2+}\right]_{\mathrm{i}}$ (more than $\sim 30$ $\mu \mathrm{M}$ ), and the difference between the two curves is smaller than that of mSlo1, demonstrating that the $\mathrm{N}$ terminus of $\mathrm{mSlo} 1$ is not the only structural component important for the $\beta 2 \mathrm{ND}$ dependent enhancement of $\mathrm{Ca}^{2+}$ sensitivity (Fig. $5 C$ ).

Previous studies have shown that the AC region (the $\beta \mathrm{A}-\alpha \mathrm{C}$ of RCK1 domain) (Krishnamoorthy et al., 2005; Yang et al., 2010) and the C-Linker (Niu et al., 2004; Krishnamoorthy et al., 2005) are important in coupling $\mathrm{Ca}^{2+}$ binding to opening of the activation gate. To examine whether this segment is also important for the $\beta 2 \mathrm{ND}$-dependent enhancement of $\mathrm{Ca}^{2+}$ sensitivity, we studied the chimera channels in which this segment from dSlo1 is transplanted into $\mathrm{mSlo} 1, \mathrm{~m}[\mathrm{dLinker}+\mathrm{dAC}$ ]. Its response to $\beta 2 \mathrm{ND}$ is estimated using $\Delta V_{\text {half }}$ (Fig. 3), which shows a dramatic reduction from that of $\mathrm{mSlo1}$ and is similar to that of dSlo1, suggesting that the $\mathrm{N}$ terminus of the cytoplasmic domain is important for the $\beta 2 \mathrm{ND}$ dependent enhancement of $\mathrm{Ca}^{2+}$ sensitivity. Surprisingly, although the inactivation "ball" is deleted in $\beta 2 \mathrm{ND}$, its association with $\mathrm{m}$ [dLinker $+\mathrm{dAC}$ ] causes inactivation of the channel (Fig. 4A). The mechanism of this inactivation is not clear at this time and needs additional study. Nevertheless, additional studies of the $\mathrm{Ca}^{2+}$ sensitivity of this chimera in several $\left[\mathrm{Ca}^{2+}\right]_{\mathrm{i}}$ shows that the $V_{1 / 2}-\left[\mathrm{Ca}^{2+}\right]_{\mathrm{i}}$ relations with and without $\beta 2 \mathrm{ND}$ superimpose (Fig. $4 C$ ), confirming that $\beta 2 \mathrm{ND}$ can no longer enhance $\mathrm{Ca}^{2+}$ sensitivity of this channel. The converse chimera in the dSlo1 background, $\mathrm{d}[\mathrm{mLinker}+\mathrm{mAC}]$ showed no increase in
$\mathrm{Ca}^{2+}$ sensitivity with the association of $\beta 2 \mathrm{ND}$ either (Fig. 5). Together, these results suggest that the $\mathrm{N}$ terminus of the cytoplasmic domain of mSlo1 is also necessary but not sufficient to account for the difference in the $\beta 2 \mathrm{ND}$-dependent increase of $\mathrm{Ca}^{2+}$ sensitivity between mSlo1 and dSlol.

Either terminus of the transmembrane or cytoplasmic domain of mSlo1 is important for the $\beta 2 \mathrm{ND}$-dependent increase of $\mathrm{Ca}^{2+}$ sensitivity, and, as expected, the chimera containing both termini from dSlo1 in the mSlo1 background, $\mathrm{m}$ [dSO + dLinker $+\mathrm{dAC}]$, showed no increase in $\mathrm{Ca}^{2+}$ sensitivity in response to $\beta 2 \mathrm{ND}$, similar to dSlo1 (Figs. 3, 4). We studied the converse chimera in dSlo1 background, $\mathrm{d}[\mathrm{mS} 0+$ mLinker + $\mathrm{mAC}$ ], to examine whether $\mathrm{N}$ termini of both the transmembrane and cytoplasmic domains of mSlo1 are sufficient to render the $\beta 2 \mathrm{ND}$-dependent increase of $\mathrm{Ca}^{2+}$ sensitivity in dSlol. However, this chimera failed to express any functional channel with $\beta 2 \mathrm{ND}$ subunit for reasons that are currently not understood. Therefore, we modified this chimera by extending the AC region to include $\beta \mathrm{G}$ of the RCK1 domain that results in $\mathrm{d}[\mathrm{mSO}+$ mLinker + mRCK1c]. The coexpression of this chimera with $\beta 2 \mathrm{ND}$ showed increased $\mathrm{Ca}^{2+}$ sensitivity that is more like mSlo1 than dSlo1 (Figs. 3, 5), suggesting that the $\mathrm{N}$ termini of the transmembrane and cytoplasmic domains of mSlol are critical for the differential $\beta 2 \mathrm{ND}$-dependent enhancement of $\mathrm{Ca}^{2+}$ sensitivity in dSlo1 and mSlo1.

The swapping of channel properties is further illustrated by fitting the $G-V$ relations of chimeras $\mathrm{m}[\mathrm{dS} 0+$ dLinker $+\mathrm{dAC}]$ 

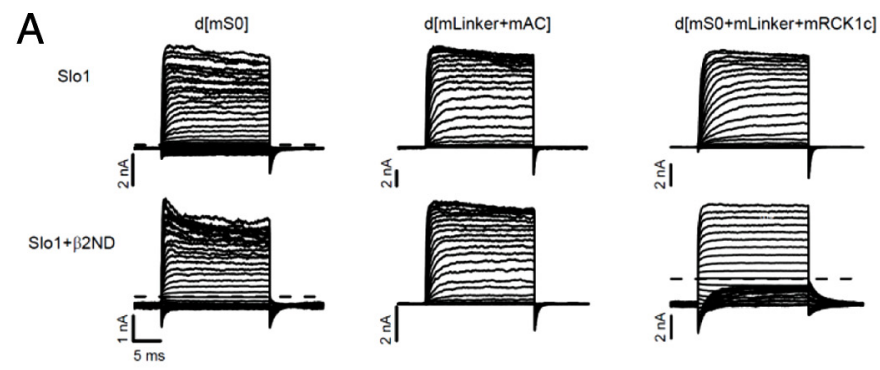

B
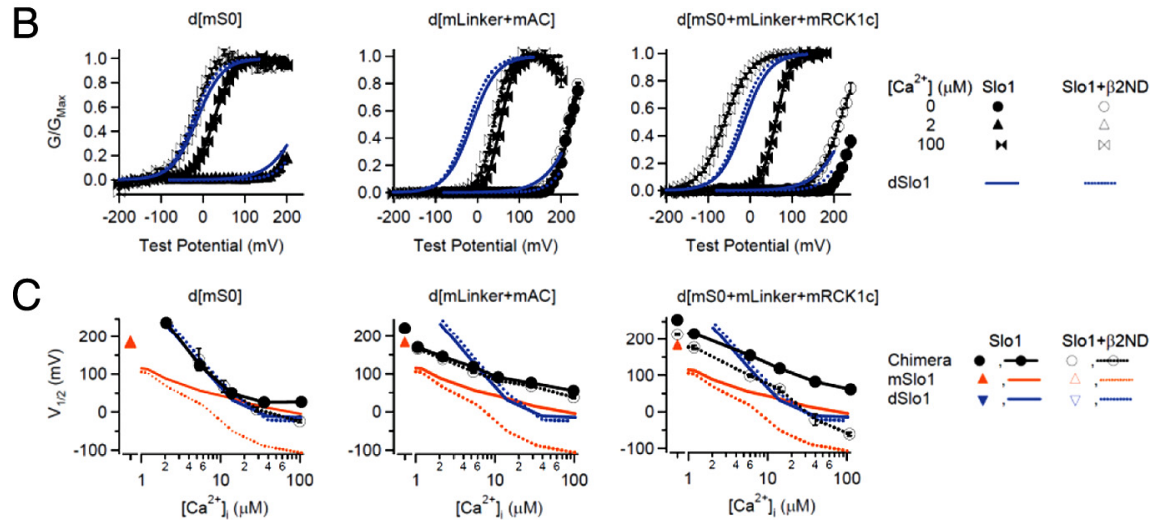

Figure 5. Effects of the N terminus and C-Linker/AC region of $\mathrm{mSl} 101$ in $\mathrm{CSl} 101$ background on the $\beta 2 \mathrm{ND}$ modulation of $\mathrm{Ca}^{2+}$ sensitivity. $\boldsymbol{A}$, Macroscopic currents ofd $[\mathrm{mSO}], \mathrm{d}[\mathrm{mL}$ inker $+\mathrm{mAC}]$, and d[mSO + mLinker $+\mathrm{mRCK1c}]$ with and without $\beta 2 \mathrm{ND}$ at $\sim 100 \mu \mathrm{m}\left[\mathrm{Ca}^{2+}\right]_{\mathrm{i}}$. Voltage pulses are from -200 to $200 \mathrm{mV}$, except for d[mSO + mLinker + mRCK1c] $+\beta 2 \mathrm{ND}$, which are from -200 to $100 \mathrm{mV}$, with 10 $\mathrm{mV}$ increments. The repolarizing potential is $-50 \mathrm{mV}$. The dashed line represents the zero current line for each current trace. $B, G-V$ relations of chimeras with and without $\beta 2 \mathrm{ND}$ at low $(0$ or $\sim 2 \mu \mathrm{m})$ and $\sim 100 \mu \mathrm{m}\left[\mathrm{Ca}^{2+}\right]_{\mathrm{i}}$ compared with that of dSlo1 (blue). $C, V_{1 / 2}$ versus $\left[\mathrm{Ca}^{2+}\right]_{i}$ plots of chimeras compared with that of $\mathrm{mSl} 1$ and $\mathrm{dSl} 01$ with and without $\beta 2 \mathrm{ND}$. The number of patches for each dataset are as follows (in $\mu \mathrm{m}$ ): $\left[\mathrm{Ca}^{2+}\right]_{\mathrm{i}, 0}, 1,2,5,10,30,100 ; \mathrm{d}[\mathrm{mSO}], 0,0,3,10,6,4,20 ; \mathrm{d}[\mathrm{mSO}]+\beta 2 \mathrm{ND}, 0,0,0,3,2,3,16 ; \mathrm{d}[\mathrm{mLinker}+\mathrm{mAC}]$, $13,5,4,4,4,4,7 ; \mathrm{d}[$ mLinker $+\mathrm{mAC}]+\beta 2 \mathrm{ND}, 23,5,3,3,5,5,13 ; \mathrm{d}[\mathrm{mSO}+\mathrm{mLinker}+\mathrm{mRCK1}], 11,2,4,7,6,16 ; \mathrm{d}[\mathrm{mSO}+\mathrm{mLinker}+$ $m R C K 1 c]+\beta 2 N D, 15,5,5,5,6,14$.

and $\mathrm{d}[\mathrm{mS} 0+$ mLinker $+\mathrm{mRCK} 1 \mathrm{c}]$ to the MWC model (Fig. 6). The association of $\beta 2 \mathrm{ND}$ with $\mathrm{m}[\mathrm{dS} 0+\mathrm{dLinker}+\mathrm{dAC}]$ produces a minor reduction in both $K_{\mathrm{C}}$ and $K_{\mathrm{O}}$ which does not change the $c$ factor (Fig. 6; Table 2), and consequently there was a lack of $G-V$ shift to negative potentials in the presence of $\mathrm{Ca}^{2+}$ (Fig. 4). However, the association of $\beta 2 \mathrm{ND}$ with $\mathrm{d}[\mathrm{mS} 0+$ mLinker + mRCK1c] increases $K_{\mathrm{C}}$ and decreases $K_{\mathrm{O}}$. These changes are in the same direction as those when $\beta 2 \mathrm{ND}$ is associated with mSlo1, which results in reduction in $c$ factor and enhanced $G-V$ shifts in response to $\left[\mathrm{Ca}^{2+}\right]_{\mathrm{i}}$ increase (Fig. 6; Table 2).

\section{Different molecular mechanisms for the $\beta 1$ - and $\beta 2$ - dependent enhancement of $\mathrm{Ca}^{2+}$ sensitivity}

Similar to the $\beta 2$ subunit, the $\beta 1$ subunit also enhances the apparent $\mathrm{Ca}^{2+}$ sensitivity of BK channels to cause a $G-V$ shift to more negative potentials in the presence of $\mathrm{Ca}^{2+}$, and the two $\beta$ subunits share a $>60 \%$ sequence homology (Brenner et al., 2000; Orio and Latorre, 2005). Furthermore, previous studies have shown that the $\beta 1$ subunit also specifically modulates $\mathrm{Ca}^{2+}$ sensitivity of the mSlo1 channel but not that of dSlo1, and the $\mathrm{N}$ terminus of mSlo1 including S0 is critical for such modulation (Wallner et al., 1996; Morrow et al., 2006). To examine whether the $\beta 1$-dependent enhancement of $\mathrm{Ca}^{2+}$ sensitivity is also sensitive to the difference between $\mathrm{mSlol}$ and $\mathrm{dSlol}$ in the $\mathrm{N}$ terminus of the cytoplasmic domain, we studied the coexpression of the $\beta 1$ subunit with the chimera $\mathrm{m}[\mathrm{dLinker}+\mathrm{dAC}]$ (Fig. 7). In the saturating $\left[\mathrm{Ca}^{2+}\right]_{\mathrm{i}}$ of $\sim 100 \mu \mathrm{M}$, the association of either the $\beta 1$ or $\beta 2 \mathrm{ND}$ subunit shifts the $G-V$ relation of $\mathrm{mSlo} 1$ to more negative potentials (Fig. $7 A$ ). The mutation $\mathrm{m}[\mathrm{dLinker}+\mathrm{dAC}]$ nearly abolishes the response of $G-V$ relation to the association of $\beta 2 \mathrm{ND}$ but not $\beta 1$ (Fig. $7 A)$. Similar results are observed in various $\left[\mathrm{Ca}^{2+}\right]_{\mathrm{i}}($ Fig. $7 B)$, indicating that the differences in the structure of $\mathrm{N}$-terminal part of the cytoplasmic domain between $\mathrm{mSlo} 1$ and dSlo1 are critical for $\beta 2$ modulation but inconsequential for $\beta 1$ function. Conversely, for chimera $\mathrm{m}[\mathrm{dS} 0] /$ $\mathrm{h}[\mathrm{dS} 0]$, there was a lack of $G-V$ shift in response to the association of both $\beta 2 \mathrm{ND}$ and $\beta 1$ (Wallner et al., 1996), indicating that the $\mathrm{N}$ terminus of the membranespanning domain is critical for the function of both the $\beta 1$ and $\beta 2$ subunits.

BK channels contain two high-affinity $\mathrm{Ca}^{2+}$ binding sites located at D367 in the RCK1 domain and the $\mathrm{Ca}^{2+}$ bowl in the RCK2 domain (Fig. 1). Previous studies show that the two binding sites have slightly different affinities for $\mathrm{Ca}^{2+}$ and they contribute independently with only a small cooperativity to $\mathrm{Ca}^{2+}$-dependent activation (Xia et al., 2002; Qian et al., 2006; Sweet and Cox, 2008). A recent study shows that mutations in the AC region specifically affect $\mathrm{Ca}^{2+}$-dependent activation derived from the D367 site but not that from the $\mathrm{Ca}^{2+}$ bowl (Yang et al., 2010). These results indicate that the two $\mathrm{Ca}^{2+}$ binding sites may couple to the activation gate through distinct structural pathways. To examine which of these pathways is affected by the $\beta$ subunits, we studied the effects of $\beta 2 \mathrm{ND}$ and $\beta 1$ on each of the pathways by mutating the $\mathrm{Ca}^{2+}$ binding site in one pathway. Mutating either $\mathrm{Ca}^{2+}$ binding site of $\mathrm{mSl} 1$ by D367A or 5D5N (five consecutive Asp residues in the $\mathrm{Ca}^{2+}$ bowl are mutated to Asn) reduced overall $G-V$ shift in response to a $\left[\mathrm{Ca}^{2+}\right]_{\mathrm{i}}$ increase from 0 to saturating $\sim 100 \mu \mathrm{M}$ in both the absence and presence of $\beta 2 \mathrm{ND}$ subunit (Fig. 8A). Nevertheless, the $G-V$ shift is larger in the presence of $\beta 2 \mathrm{ND}$ (Fig. $8 A$, gray bars). When both $\mathrm{Ca}^{2+}$ binding sites are mutated, channel activation is no longer sensitive to $\mathrm{Ca}^{2+}$ in either the presence or absence of $\beta 2 \mathrm{ND}$ (Fig. 8). These results indicate that the $\beta 2$ subunit modulates mSlol activation as long as at least one $\mathrm{Ca}^{2+}$ binding site is intact. Interestingly, regardless of whether one or both $\mathrm{Ca}^{2+}$ binding sites are intact, the association of $\beta 2 \mathrm{ND}$ results in similar increase of $G-V$ shift (Fig. $8 B$ ). To the contrary, although the $\beta 1$ subunit also modulates mSlo 1 activation as long as at least one $\mathrm{Ca}^{2+}$ binding site is intact (Fig. $8 \mathrm{~A}$, white bars), the mutation of either $\mathrm{Ca}^{2+}$ binding site reduces the ability of $\beta 1$ to increase $G-V$ shift (Fig. $8 B$ ). This result suggests that, although $\beta 1$ subunit is primarily known to affect the voltage-dependent activation (Cox and Aldrich, 2000; Bao and Cox, 2005; Orio and Latorre, 2005; Yang et al., 2008), it may also be sensitive to the integrity of the $\mathrm{Ca}^{2+}$ binding site, which is supported by Bao and Cox (2005). Together, these experiments indicate that the $\beta$ subunits modulate both pathways of $\mathrm{Ca}^{2+}$ dependent activation, but the $\beta 1$ and $\beta 2$ subunits may target different points in the $\mathrm{Ca}^{2+}$-dependent activation. Based on the recently published structures of the $\mathrm{BK}$ channel gating ring, the Linker and AC region reside closest to the pore (Wu et al., 2010; Yuan et al., 2010), which is the sole structural gateway to couple 

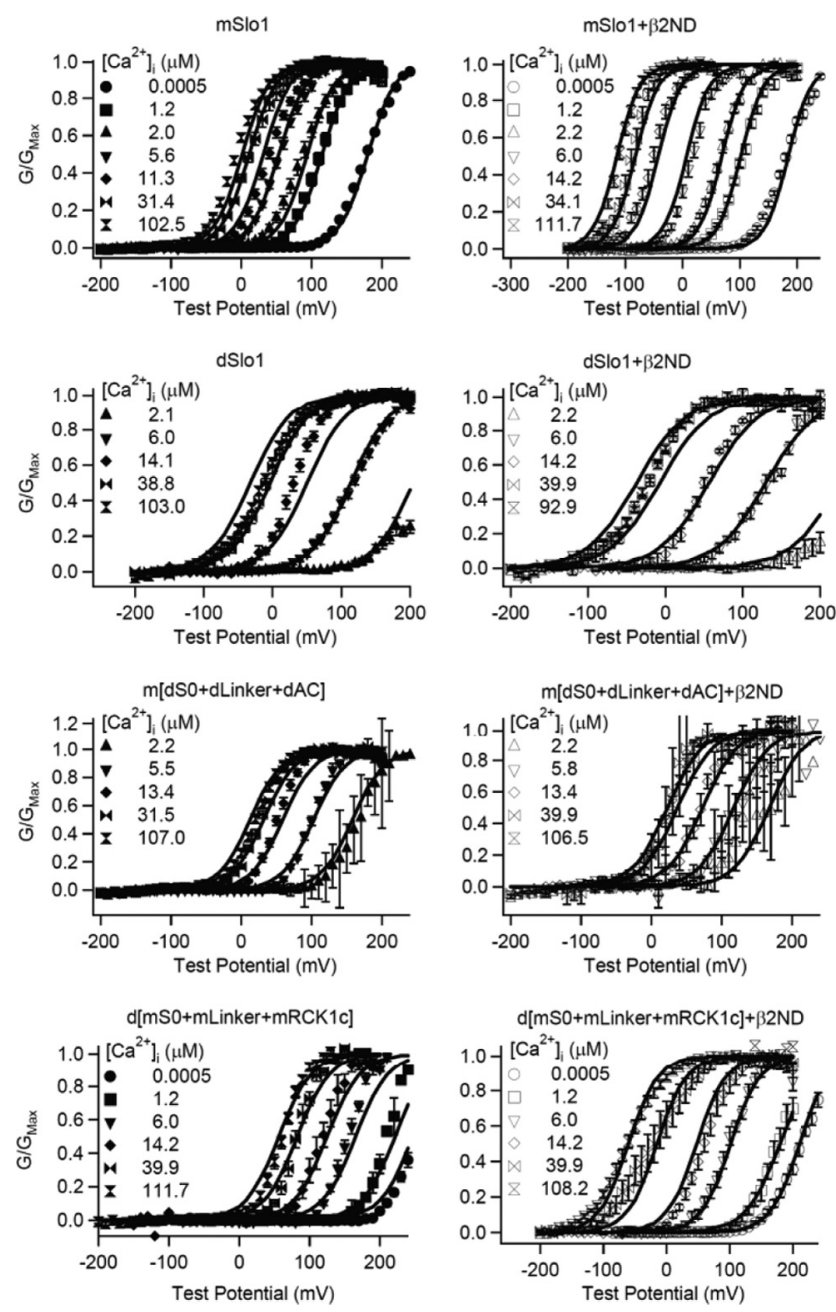

Figure 6. MWC model fittings of WT and chimera channels. $G-V$ relationships (symbols) for $\mathrm{mSl} 01, \mathrm{dSl} 01, \mathrm{~m}[\mathrm{dSO}+\mathrm{dLinker}+\mathrm{dAC}]$, and d[mSO + mLinker $+\mathrm{mRCK} 1 \mathrm{c}]$ with and without $\beta 2 N D$ fitted with the MWC model (lines). The $\left[\mathrm{Ca}^{2+}\right]_{\mathrm{i}}$ for each symbol is shown.

both $\mathrm{Ca}^{2+}$ binding sites to the activation gate (Fig. 9). The $\beta 2$ subunit may directly modify the allosteric mechanism in this region to affect the coupling between $\mathrm{Ca}^{2+}$ binding and channel opening. The $\beta 1$ subunit, conversely, may alter the coupling between $\mathrm{Ca}^{2+}$ binding and channel opening via different mechanisms, possibly involving the VSD. The difference of the two $\beta$ subunits in response to $\mathrm{Ca}^{2+}$ binding site mutations may be the manifestations of such mechanistic differences. However, the exact nature of these allosteric mechanisms are not fully understood.

\section{Discussion}

The $\beta$ subunits of $\mathrm{BK}$ channels modulate specific properties of the pore-forming Slo1 subunit. In the case of the $\beta 2$ subunit, the BK channels exhibit increased $\mathrm{Ca}^{2+}$ sensitivity by shifting the $V^{1 / 2}$ to more negative potentials with increasing $\left[\mathrm{Ca}^{2+}\right]_{\mathrm{i}}$. In this study, we identified the regions in Slo 1 targeted by the $\beta 2$ subunit modulation by taking advantage of different responses of two BK channel homologs, mSlo1 and dSlo1, to the $\beta 2$ subunit modulation. We found two regions in mSlol that are both necessary and sufficient to account for the enhanced $\mathrm{Ca}^{2+}$ sensitivity with the $\beta 2$ subunit compared with dSlo1: the $\mathrm{N}$ terminus of the channel to $\mathrm{S} 0$ and the $\mathrm{N}$ terminus of the cytoplasmic domain, C-Linker/ $\mathrm{AC}$ region. Both of these structural regions from $\mathrm{mSlol}$ are re-
A
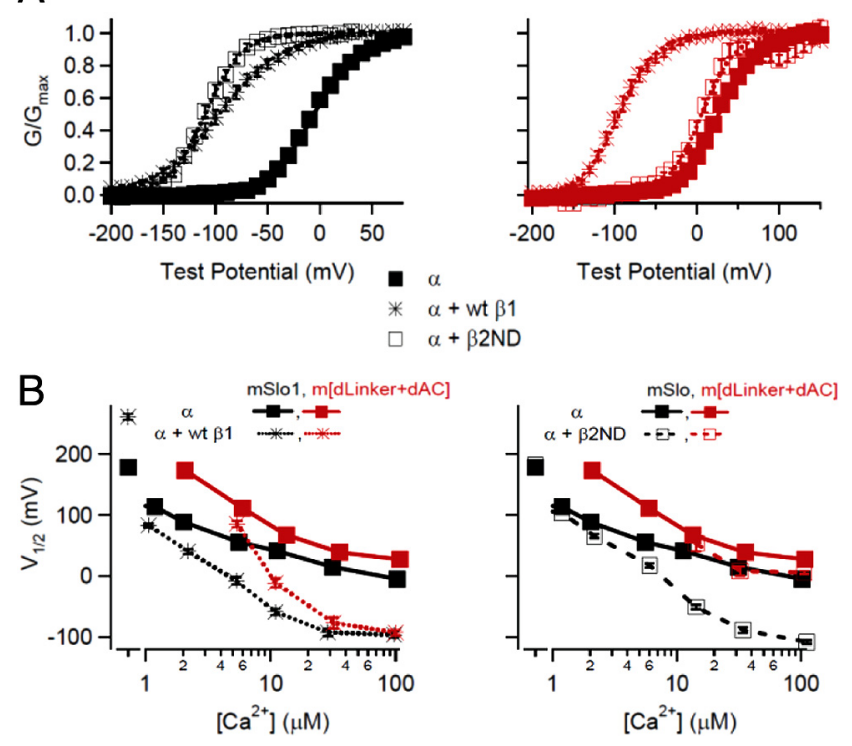

Figure 7. The role of the $\mathrm{C}-$ Linker and $\mathrm{AC}$ region of $\mathrm{mSl} 101$ in the $\beta 1$ and $\beta 2 \mathrm{ND}$ modulation of $\mathrm{Ca}^{2+}$ sensitivity. $A, G-V$ relations of $\mathrm{mSl} 101$ and $\mathrm{m}[\mathrm{dLinker}+\mathrm{dAC}]$ with and without $\beta 1$ or $\beta 2 \mathrm{ND}$ in $\sim 100 \mu \mathrm{m}\left[\mathrm{Ca}^{2+}\right]_{\mathrm{i}} . \boldsymbol{B}, V_{1 / 2}$ versus $\left[\mathrm{Ca}^{2+}\right]_{i}$ plots of $\mathrm{mSl} 1$ and $\mathrm{m}[\mathrm{dLinker}+\mathrm{dAC}$ with $\beta 1$ (left) or $\beta 2 \mathrm{ND}$ (right). The number of patches are as follows (in $\mu \mathrm{M}$ ): $\left[\mathrm{Ca}^{2+}\right]_{\mathrm{i}}, 0,1,2,5,10,30,100$ : $\mathrm{mSl} 101+\beta 1,38,13,15,11,12,8,21$; $\mathrm{m}[\mathrm{d}$ Linker + $d A C]+\beta 1,0,0,0,10,6,9,26$.
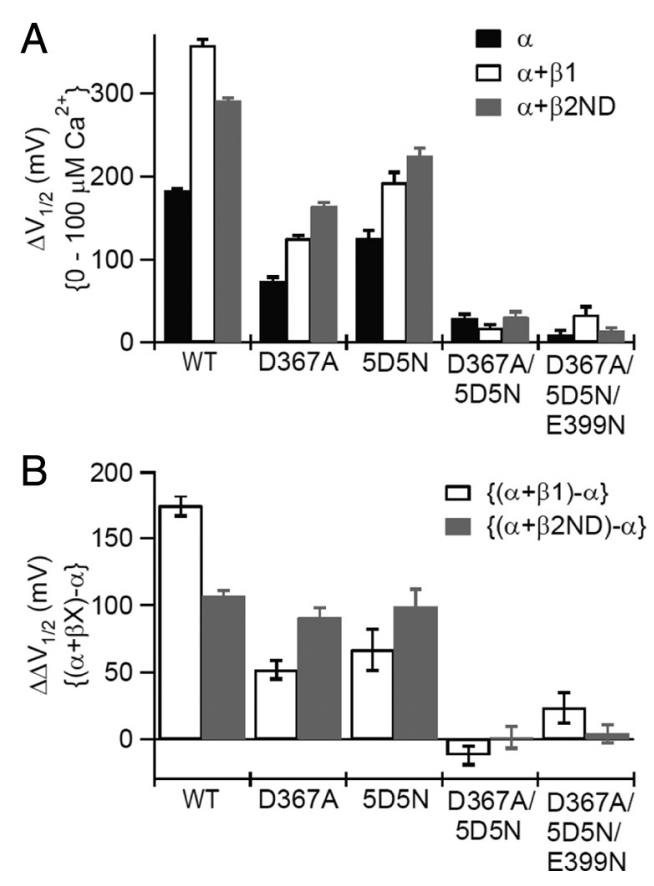

Figure 8. Dependence of the $\beta 1$ and $\beta 2$ modulation of $\mathrm{Ca}^{2+}$ sensitivity on $\mathrm{Ca}^{2+}$ binding sites in $\mathrm{mSl}$ 01. A, Bar graph of the $\mathrm{G}-V$ shift in response to a $\left[\mathrm{Ca}^{2+}\right]_{\mathrm{i}}$ change from $0-100 \mu \mathrm{M}$ WT, single $\mathrm{Ca}^{2+}$ binding site mutations (D367A and 5D5N), double $\mathrm{Ca}^{2+}$ binding site mutation (D367A/5D5N), and double $\mathrm{Ca}^{2+}$ binding site plus the $\mathrm{Mg}^{2+}$ binding site mutation (D367A/ $5 D 5 N / E 399 N)$ without (black) and with $\beta 1$ (white) or $\beta 2 N D$ (gray). $B$, Differences in $\Delta V_{1 / 2}$ from $A$ of $\beta 1$ (white) and $\beta 2$ ND (gray) with WT, single, double, and triple binding site mutations. The number of patches for each dataset are as follows for $\sim 0$ and $\sim 100 \mu \mathrm{M}\left[\mathrm{Ca}^{2+}\right]_{\text {, }}$ respectively: $\mathrm{mD} 367 \mathrm{~A}, 10,9 ; \mathrm{mD} 367 \mathrm{~A}+\beta 1,9,9 ; \mathrm{mD} 367 \mathrm{~A}+\beta 2 \mathrm{ND}, 5,7 ; 5 \mathrm{D} 5 \mathrm{~N}, 6,11 ; 5 \mathrm{DNN}+\beta 1,8,9$; $5 \mathrm{D} 5 \mathrm{~N}+\beta 2 \mathrm{ND}, 4,8 ; \mathrm{mD} 367 \mathrm{~A} / 5 \mathrm{D} 5 \mathrm{~N}, 14,6 ; \mathrm{mD} 367 \mathrm{~A} / 5 \mathrm{D} 5 \mathrm{~N}+\beta 1,6,5 ; \mathrm{mD367A} / 5 \mathrm{D} 5 \mathrm{~N}+$ $\beta 2 \mathrm{ND}, 5,5 ; \mathrm{mD} 367 \mathrm{~A} / 5 \mathrm{D} 5 \mathrm{~N} / \mathrm{E} 399 \mathrm{~N}, 15,15 ; \mathrm{mD} 367 \mathrm{~A} / 5 \mathrm{D} 5 \mathrm{~N} / \mathrm{E} 399 \mathrm{~N}+\beta 1,5,9 ; \mathrm{mD} 367 \mathrm{~A} / 5 \mathrm{D} 5 \mathrm{~N} /$ $\mathrm{E} 399 \mathrm{~N}+\beta 2 \mathrm{ND}, 8,12$. 


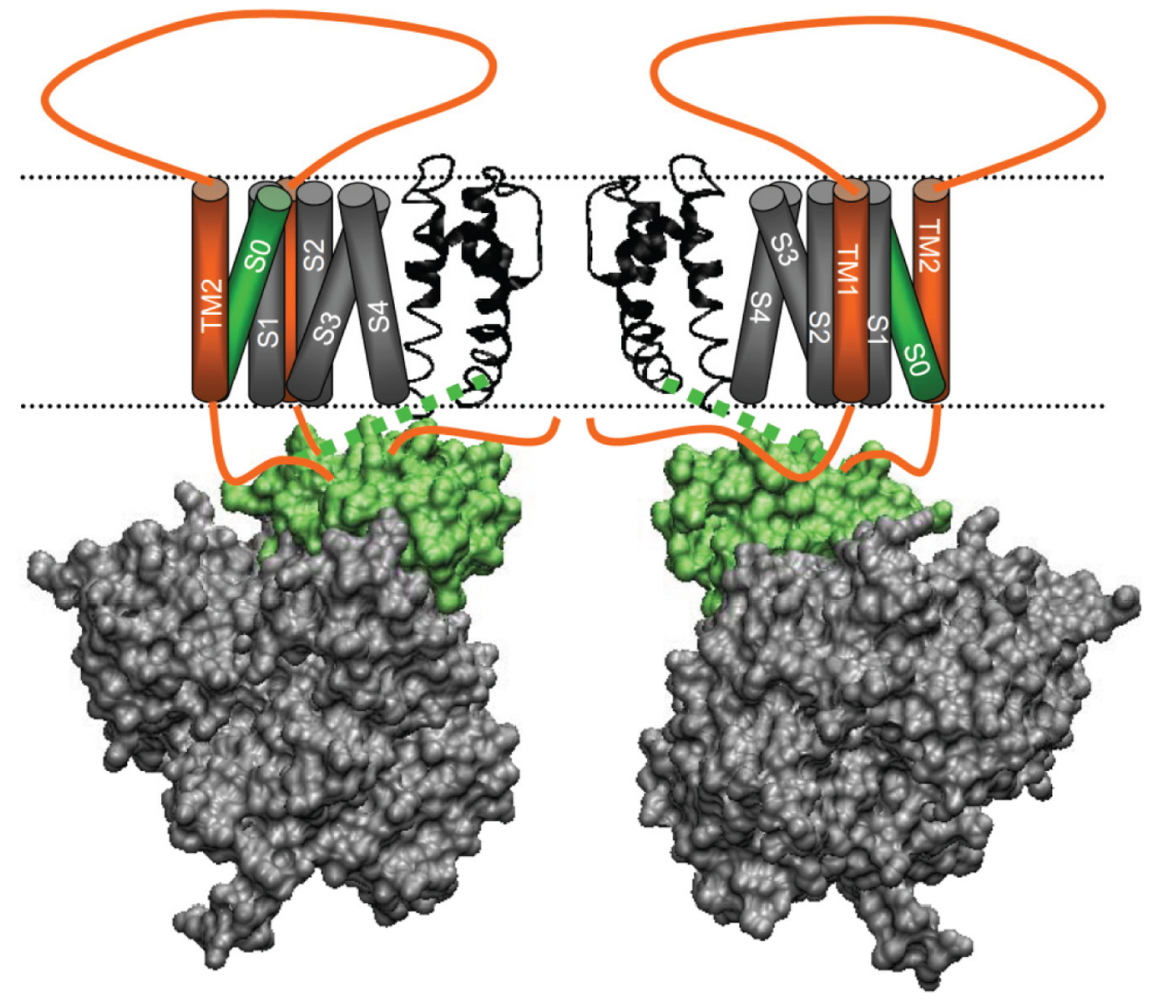

Figure 9. A structural model for the $\beta 2$ subunit modulation. Two opposing mSlo 1 and $\beta 2$ (orange) subunits of BK channels are shown in which the diagrams for the VSD and SO segment are constructed around the pore of the MthK channel (Protein Data Bank identification number 1LNQ) (Jiang et al., 2002). The gating ring of the BK channel (Protein Data Bank identification number 3MT5) (Yuan et al., 2010) is aligned to the MthK channel using Chimera version 1.4.1 (University of California, San Francisco). VMD (Visual Molecular Dynamics) version 1.8.7 (University of Illinois at Urbana-Champaign) was used to show the aligned structure in diagram and surface representation. The helices in the VSD are shown as cylinders and are positioned according to the $K_{V} 1.2$ channel. The TM segments of the $\beta 2$ subunit are positioned according to Zakharov et al. (2009). Green regions in the Slo1 subunit (SO, C-Linker and $\mathrm{AC})$ are involved in the $\beta 2$ modulation of $\mathrm{Ca}^{2+}$ sensitivity.

quired for conferring $\mathrm{Ca}^{2+}$ sensitivity in dSlo1, but the replacement of either one in $\mathrm{mSlol}$ by the counterpart in dSlo1 reduced or abolished the $\beta 2$-dependent $\mathrm{Ca}^{2+}$ sensitivity increase.

The $\mathrm{N}$ terminus of mSlol including $\mathrm{S} 0$ is important for both the $\beta 1$ and $\beta 2$ subunits to enhance $\mathrm{Ca}^{2+}$ sensitivity of channel activation (Figs. 3, 5) (Wallner et al., 1996; Morrow et al., 2006), which is consistent with the structural and functional role of S0. Using disulfide cross-linking, Liu et al. (2008a, 2010) showed that $\mathrm{S} 0$ is an integral part of the voltage-sensing domain of BK channels; its N-terminal extracellular end is close to that of S3 and S4. Consistently, mutations in S0 alter voltage dependence of channel activation, suggesting that it may interact with other membrane-spanning segments of the VSD (Koval et al., 2007). Similar disulfide cross-linking studies revealed that, when the $\beta 1$ (Liu et al., 2008b, 2010), $\beta 2$ (Zakharov et al., 2009), and $\beta 4$ (Wu et al., 2009) subunits associate with Slo1, TM2 is located close to S0 while TM1 is located close to S2. These results suggest that S0 may directly interact with the TM2 of $\beta$ subunits, whereas the VSD may serve as a scaffold for the conformation of $\beta$ subunits. Both the $\beta 1$ and $\beta 2$ subunits are unable to enhance $\mathrm{Ca}^{2+}$ sensitivity of dSlol (Wallner et al., 1996), and a switch of the $\mathrm{N}$ terminus and $\mathrm{S} 0$ of $\mathrm{mSlo} 1$ to that of $\mathrm{dSlo} 1$ reduces the function of both $\beta$ subunits. These results may arise because, although the $\beta$ subunits can associate with dSlo 1 (Fig. 2), the S0 of dSlo1 may alter either the direct TM2-S0 interaction or the structure of the VSD that leads to a conformational change in $\beta$ subunits.
Contrary to the $\mathrm{N}$ terminus of the channel, the C-Linker and $\mathrm{AC}$ region of mSlol are specifically important for the $\beta 2$, but not $\beta 1$, subunit to modulate $\mathrm{Ca}^{2+}$ sensitivity (Fig. 7). This result is consistent with previous findings that the cytoplasmic termini of the $\beta 1$ and $\beta 2$ subunits are important in determining their specific effects on channel gating (Orio et al., 2006; Wang and Brenner, 2006). Taking these results together, it is likely that the $\mathrm{C}$-Linker and AC region of Slo1 may interact with the cytosolic domain of the $\beta 2$ subunit either directly or through an allosteric mechanism. Previous studies show that changes in the length of the C-Linker alter $\mathrm{Ca}^{2+}$ sensitivity of the channel (Niu et al., 2004), whereas mutations in the AC region revealed an allosteric network important for $\mathrm{Ca}^{2+}$ dependence of channel gating (Krishnamoorthy et al., 2005; Yang et al., 2010). Our results further support the important role of the C-Linker and AC region in mediating the coupling between $\mathrm{Ca}^{2+}$ binding and channel opening and show that the $\beta 2$ subunit may modulate $\mathrm{Ca}^{2+}$ sensitivity by altering such coupling. Conversely, the switch of the $\mathrm{C}$-Linker and $\mathrm{AC}$ region from mSlo1 to that of dSlo 1 has no effect on the $\beta 1$ modulation of $\mathrm{Ca}^{2+}$ sensitivity (Fig. 7). This result could be attributable to the fact that $\beta 1$ does not interact with the C-Linker or $\mathrm{AC}$ region so that it is not sensitive to the switch of these regions between mSlo1 and dSlo1. Alternatively, $\beta 1$ may interact with these regions but the interaction differs from how $\beta 2 \mathrm{ND}$ interacts with these regions such that $\beta 1$ is insensitive to the differences between mSlol and dSlol in these regions. Because of the inherited limitations of chimera studies, our results cannot distinguish these two possibilities. Nevertheless, it is clear that the two $\beta$ subunits interact with the structural domains in Slo1 differently, which is consistent with previous studies showing that the $\beta 1$ subunit alters the voltage sensor movements (Cox and Aldrich, 2000), and mutations in the VSD of Slol alter the modulation of the $\beta 1$ but not the $\beta 2$ subunit (Yang et al., 2008). These results provide a molecular mechanism for the previous results obtained by fitting of functional data to an allosteric model for channel activation, which show that the $\beta 2$ subunit alters $\mathrm{Ca}^{2+}$ binding affinities and allosteric coupling factors, whereas the $\beta 1$ subunit has less effects on parameters for $\mathrm{Ca}^{2+}$-dependent activation (Bao and Cox, 2005; Orio and Latorre, 2005).

These experimental results suggest a model in which the TM1 and TM2 segments of the $\beta 2$ subunit associate with the VSD of mSlo1, whereas the cytoplasmic termini of the $\beta 2$ subunit may interact with the $\mathrm{C}$-Linker and $\mathrm{AC}$ region in $\mathrm{mSlol}$ to alter the coupling between $\mathrm{Ca}^{2+}$ binding and channel opening, thereby enhancing $\mathrm{Ca}^{2+}$ sensitivity of channel gating (Fig. 9). The interaction between the $\beta 2$ subunit with S0 and other parts of the VSD may help the $\beta 2$ subunit adopt a correct conformation and a proper orientation toward the mSlol that are critical for its cytoplasmic termini to interact with the C-Linker and AC region. Therefore, mutations in either $\mathrm{S} 0$ and the $\mathrm{N}$ terminus of the 
channel or the C-Linker and AC region may interrupt the interactions between the cytoplasmic termini of $\beta 2$ with the $\mathrm{C}$-Linker and $\mathrm{AC}$ region to reduce or abolish the $\beta 2$ modulation of $\mathrm{Ca}^{2+}$ sensitivity.

Besides S0, other structures in Slo1 may also affect the conformation of the $\beta 2$ subunit and its orientation toward Slo1. For instance, for chimera $\mathrm{m}[\mathrm{dSO}]$, in which the $\mathrm{N}$ terminus including $\mathrm{S} 0$ of $\mathrm{mSlo} 1$ is replaced by the counterpart of dSlo1, the $\beta 2$ subunit still increases $\mathrm{Ca}^{2+}$ sensitivity, although the effect is mostly reduced (Fig. 3 ), indicating that the $\beta 2$ subunit remains in a conformation and orientation toward Slo1 that still allows some interaction with the $\mathrm{C}$-Linker and $\mathrm{AC}$ region. Conversely, chimera $\mathrm{C} 5$, in which an additional structure of $\mathrm{mSlo} 1$ is replaced by the counterpart of dSlo1, further reduces the $\beta 2$ modulation of $\mathrm{Ca}^{2+}$ sensitivity (Fig. 3). This result indicates that the S0-S1 linker and $\mathrm{S} 1$ of $\mathrm{mSlo} 1$ may also participate in the $\beta 2$-dependent enhancement of $\mathrm{Ca}^{2+}$ sensitivity (Fig. 3), possibly being involved in maintaining the conformation of the $\beta 2$ subunit. To test this theory, $\mathrm{N}$ terminus to $\mathrm{S} 1$ segment of $\mathrm{mSlol}$ were transplanted in $\mathrm{dSlo} 1$ to test whether the $\mathrm{C}$-Linker and AC region of mSlo1 is still required for the $\beta 2$ modulation of $\mathrm{Ca}^{2+}$ sensitivity. However, because of a large shift in its $G-V$ relation to positive voltages, it is difficult to determine the modulation of $\mathrm{Ca}^{2+}$ sensitivity by the $\beta 2$ subunit (data not shown).

The $\beta 2$ subunit enhances $\mathrm{Ca}^{2+}$ sensitivity of $\mathrm{mSlo} 1$ channels but has little effect on channel activation in the absence of $\mathrm{Ca}^{2+}$ (Figs. 2, 6; Table 2). Interestingly, for $\mathrm{d}[\mathrm{mSO}+$ mLinker + mRCK1c] channels, the association of the $\beta 2 \mathrm{ND}$ subunit results in a large shift of the $G-V$ relation in the absence of intracellular $\mathrm{Ca}^{2+}$ (Fig. 5), indicating a change in the equilibrium between the open and closed conformation (Fig. 6; Table 2). This result indicates that the $\beta 2$ subunit not only alters the $\mathrm{Ca}^{2+}$-dependent mechanism to enhance $\mathrm{Ca}^{2+}$ sensitivity but also affects the structure and mechanism important for channel opening in the absence of $\mathrm{Ca}^{2+}$. These results are consistent with the previously reported results of an allosteric model fitting of BK channel gating, which showed that the enhancement of $\mathrm{Ca}^{2+}$ sensitivity by the $\beta 2$ subunit requires changes to the allosteric coupling factors and intrinsic channel opening (Orio and Latorre, 2005). Such an effect of the $\beta 2$ subunit may arise from its interactions with the membrane-spanning segments and VSD of Slo1 or with the $\mathrm{C}$-Linker and RCK domains. It could also arise from the possibility that the association of the $\beta 2$ subunit alters the interactions between the membrane-spanning and cytoplasmic domains of Slo1 that are critical for BK channel activation. These mechanisms may also contribute to the modulation of the $\beta 2$ subunit on $\mathrm{Ca}^{2+}$ sensitivity.

\section{References}

Adelman JP, Shen KZ, Kavanaugh MP, Warren RA, Wu YN, Lagrutta A, Bond CT, North RA (1992) Calcium-activated potassium channels expressed from cloned complementary DNAs. Neuron 9:209-216.

Bao L, Cox DH (2005) Gating and ionic currents reveal how the BKCa channel's $\mathrm{Ca}^{2+}$ sensitivity is enhanced by its betal subunit. J Gen Physiol 126:393-412.

Brayden JE, Nelson MT (1992) Regulation of arterial tone by activation of calcium-dependent potassium channels. Science 256:532-535.

Brenner R, Jegla TJ, Wickenden A, Liu Y, Aldrich RW (2000) Cloning and functional characterization of novel large conductance calcium-activated potassium channel beta subunits, hKCNMB3 and hKCNMB4. J Biol Chem 275:6453-6461.

Butler A, Tsunoda S, McCobb DP, Wei A, Salkoff L (1993) mSlo, a complex mouse gene encoding "maxi" calcium-activated potassium channels. Science 261:221-224.

Cox DH, Aldrich RW (2000) Role of the betal subunit in large-conductance
$\mathrm{Ca}^{2+}$-activated $\mathrm{K}^{+}$channel gating energetics. Mechanisms of enhanced $\mathrm{Ca}^{2+}$ sensitivity. J Gen Physiol 116:411-432.

Cox DH, Cui J, Aldrich RW (1997) Allosteric gating of a large conductance Ca-activated $\mathrm{K}^{+}$channel. J Gen Physiol 110:257-281.

Cui J, Aldrich RW (2000) Allosteric linkage between voltage and $\mathrm{Ca}^{2+}$ dependent activation of BK-type mslol $\mathrm{K}^{+}$channels. Biochemistry (Mosc) 39:15612-15619.

Ding JP, Li ZW, Lingle CJ (1998) Inactivating BK channels in rat chromaffin cells may arise from heteromultimeric assembly of distinct inactivationcompetent and noninactivating subunits. Biophys J 74:268-289.

Hicks GA, Marrion NV (1998) $\mathrm{Ca}^{2+}$-dependent inactivation of large conductance $\mathrm{Ca}^{2+}$-activated $\mathrm{K}^{+}(\mathrm{BK})$ channels in rat hippocampal neurones produced by pore block from an associated particle. J Physiol 508: $721-734$

Horrigan FT, Aldrich RW (2002) Coupling between voltage sensor activation, $\mathrm{Ca}^{2+}$ binding and channel opening in large conductance (BK) potassium channels. J Gen Physiol 120:267-305.

Jiang Y, Lee A, Chen J, Cadene M, Chait BT, MacKinnon R (2002) Crystal structure and mechanism of a calcium-gated potassium channel. Nature 417:515-522.

Koval OM, Fan Y, Rothberg BS (2007) A role for the S0 transmembrane segment in voltage-dependent gating of BK channels. J Gen Physiol 129:209-220.

Krishnamoorthy G, Shi J, Sept D, Cui J (2005) The NH2 terminus of RCK1 domain regulates $\mathrm{Ca}^{2+}$-dependent $\mathrm{BK}(\mathrm{Ca})$ channel gating. J Gen Physiol 126:227-241.

Lancaster B, Nicoll RA (1987) Properties of two calcium-activated hyperpolarizations in rat hippocampal neurones. J Physiol 389:187-203.

Lee US, Cui J (2009) $\beta$ subunit-specific modulations of BK channel function by a mutation associated with epilepsy and dyskinesia. J Physiol 587:1481-1498

Liu G, Zakharov SI, Yang L, Deng SX, Landry DW, Karlin A, Marx SO (2008a) Position and role of the BK channel alpha subunit S0 helix inferred from disulfide crosslinking. J Gen Physiol 131:537-548.

Liu G, Zakharov SI, Yang L, Wu RS, Deng SX, Landry DW, Karlin A, Marx SO (2008b) Locations of the betal transmembrane helices in the BK potassium channel. Proc Natl Acad Sci U S A 105:10727-10732.

Liu G, Niu X, Wu RS, Chudasama N, Yao Y, Jin X, Weinberg R, Zakharov SI, Motoike H, Marx SO, Karlin A (2010) Location of modulatory beta subunits in BK potassium channels. J Gen Physiol 135:449-459.

Marty A (1981) Ca-dependent K channels with large unitary conductance in chromaffin cell membranes. Nature 291:497-500.

Meera P, Wallner M, Song M, Toro L (1997) Large conductance voltageand calcium-dependent $\mathrm{K}^{+}$channel, a distinct member of voltagedependent ion channels with seven $\mathrm{N}$-terminal transmembrane segments (S0-S6), an extracellular $\mathrm{N}$ terminus, and an intracellular (S9-S10) C terminus. Proc Natl Acad Sci U S A 94:14066-14071.

Morrow JP, Zakharov SI, Liu G, Yang L, Sok AJ, Marx SO (2006) Defining the BK channel domains required for betal-subunit modulation. Proc Natl Acad Sci U S A 103:5096-5101.

Niu X, Qian X, Magleby KL (2004) Linker-gating ring complex as passive spring and $\mathrm{Ca}^{2+}$-dependent machine for a voltage- and $\mathrm{Ca}^{2+}$-activated potassium channel. Neuron 42:745-756.

Orio P, Latorre R (2005) Differential effects of beta 1 and beta 2 subunits on BK channel activity. J Gen Physiol 125:395-411.

Orio P, Rojas P, Ferreira G, Latorre R (2002) New disguises for an old channel: MaxiK channel beta-subunits. News Physiol Sci 17:156-161.

Orio P, Torres Y, Rojas P, Carvacho I, Garcia ML, Toro L, Valverde MA, Latorre R (2006) Structural determinants for functional coupling between the beta and alpha subunits in the $\mathrm{Ca}^{2+}$-activated $\mathrm{K}^{+}(\mathrm{BK})$ channel. J Gen Physiol 127:191-204.

Qian X, Niu X, Magleby KL (2006) Intra- and intersubunit cooperativity in activation of BK channels by $\mathrm{Ca}^{2+}$. J Gen Physiol 128:389-404.

Schreiber M, Salkoff L (1997) A novel calcium-sensing domain in the BK channel. Biophys J 73:1355-1363.

Shi J, Krishnamoorthy G, Yang Y, Hu L, Chaturvedi N, Harilal D, Qin J, Cui J (2002) Mechanism of magnesium activation of calcium-activated potassium channels. Nature 418:876-880.

Storm JF (1987) Action potential repolarization and a fast afterhyperpolarization in rat hippocampal pyramidal cells. J Physiol 385:733-759.

Sweet TB, Cox DH (2008) Measurements of the BKCa channel's high- 
affinity $\mathrm{Ca}^{2+}$ binding constants: effects of membrane voltage. J Gen Physiol 132:491-505.

Wallner M, Meera P, Toro L (1996) Determinant for beta-subunit regulation in high-conductance voltage-activated and $\mathrm{Ca}^{2+}$-sensitive $\mathrm{K}^{+}$channels: an additional transmembrane region at the $\mathrm{N}$ terminus. Proc Natl Acad Sci U S A 93:14922-14927.

Wallner M, Meera P, Toro L (1999) Molecular basis of fast inactivation in voltage and $\mathrm{Ca}^{2+}$-activated $\mathrm{K}^{+}$channels: a transmembrane beta-subunit homolog. Proc Natl Acad Sci U S A 96:4137-4142.

Wang B, Brenner R (2006) An S6 mutation in BK channels reveals beta1 subunit effects on intrinsic and voltage-dependent gating. J Gen Physiol 128:731-744.

Wu RS, Chudasama N, Zakharov SI, Doshi D, Motoike H, Liu G, Yao Y, Niu X, Deng SX, Landry DW, Karlin A, Marx SO (2009) Location of the $\beta 4$ transmembrane helices in the BK potassium channel. J Neurosci 29:8321-8328.

Wu Y, Yang Y, Ye S, Jiang Y (2010) Structure of the gating ring from the human large-conductance $\mathrm{Ca}^{2+}$-gated $\mathrm{K}^{+}$channel. Nature 466:393-397.

Xia XM, Ding JP, Lingle CJ (1999) Molecular basis for the inactivation of $\mathrm{Ca}^{2+}$ - and voltage-dependent BK channels in adrenal chromaffin cells and rat insulinoma tumor cells. J Neurosci 19:5255-5264.
Xia XM, Zeng X, Lingle CJ (2002) Multiple regulatory sites in largeconductance calcium-activated potassium channels. Nature 418:880884

Xia XM, Ding JP, Lingle CJ (2003) Inactivation of BK channels by the NH2 terminus of the beta2 auxiliary subunit: an essential role of a terminal peptide segment of three hydrophobic residues. J Gen Physiol 121:125-148.

Yang H, Zhang G, Shi J, Lee US, Delaloye K, Cui J (2008) Subunit-specific effect of the voltage sensor domain on $\mathrm{Ca}^{2+}$ sensitivity of BK channels. Biophys J 94:4678-4687.

Yang J, Krishnamoorthy G, Saxena A, Zhang G, Shi J, Yang H, Delaloye K, Sept D, Cui J (2010) An epilepsy/dyskinesia-associated mutation enhances $\mathrm{BK}$ channel activation by potentiating $\mathrm{Ca}^{2+}$ sensing. Neuron 66:871-883.

Yuan P, Leonetti MD, Pico AR, Hsiung Y, MacKinnon R (2010) Structure of the human $\mathrm{BK}$ channel $\mathrm{Ca}^{2+}$-activation apparatus at $3.0 \mathrm{~A}$ resolution. Science 329:182-186.

Zakharov SI, Wu RS, Liu G, Motoike H, Karlin A, Marx SO (2009) Locations of the beta 2 transmembrane helices in the BK potassium channel. Presented at the 53rd Annual Biophysical Society Meeting, Boston, February-March. 